\title{
Robust Bi-Objective Operating Rooms Scheduling Problem Regarding the Shared Resources
}

Soheil Hasannia-Kolagar; Department of industrial engineering; Babol Noshirvani University of Technology; Babol; Iran; Mobile: +989194147108

Ebrahim Asadi-Gangraj*; Department of industrial engineering; Babol Noshirvani University of Technology; Babol; Iran; Tel: +981135501814; Mobile: +989112218300

Mohammad Mahdi Paydar; Department of industrial engineering; Babol Noshirvani University of Technology; Babol; Iran; Tel: +981135501817

Novin Nikbakhsh; Department of surgery; Babol University of Medical Sciences; Babol; Iran; Tel: $+981132256653$

*Corresponding author: Ebrahim Asadi-Gangraj; Email: E.asadi@nit.ac.ir;

\begin{abstract}
In recent years, many efforts have been made to provide different strategies for enhancing the scheduling and planning of the operating rooms. The efficient planning and scheduling of ORs is a complex task since it has to account for the availability of human resources, medical equipment, and medication required for each surgery but that are often shared between different ORs. This paper proposes a mathematical approach to enhance the management of OR resources. It presents a bi-objective robust optimization approach for scheduling the surgeries in the ORs and recovery room, regarding the uncertainty of the surgery time, uncertainty of hospitalization time in the recovery room, and shared resources. The first objective function aims to minimize the maximum completion time of the surgeries and the second one minimizes the sum of the earliness-tardiness of the surgical operations. The suggested approach utilizes the multi-choice goal programming approach with utility function to solve the proposed model. The proposed approach is applied to a real case in the Shahid Beheshti hospital, Babol, Iran. The obtained results show that the suggested biobjective robust optimization approach can enhance OR scheduling and should be designed into a decision support system for OR management.
\end{abstract}

Keywords: Scheduling; Operating Rooms; Multi-choice goal programming; Shared resources; Uncertainty

\section{Introduction}

Operating room (OR) is one of the most vital but also expensive parts of a hospital. Due to the importance of surgical services in the hospital, the operating room is known as the heart of the hospital. In fact, it allows for surgical services for patients who require an offensive operation (surgery). Proper scheduling of surgical operations and other related limited resources is so important for the stakeholders (managers, staff, and patients) to improve the effectiveness of staff and resources and to increase satisfaction in serving patients, satisfaction of the staff, maintaining capital, and reducing costs [1]. The efficient scheduling of the sections before and after the ORs can reduce the patients' waiting and hospitalization time [2]. This reduction further contributes to both reducing costs and increasing the satisfaction of patients and employees [3]. OR scheduling follows patient prioritization; accordingly, a patient in an emergency condition is more 
important and should be surgically activated sooner [4]. Meanwhile, the availability of limited resources and the type of surgery are important factors to be scheduled in OR surgery planning [5].

A priori undetermined factors of surgeries, such as patients' conditions, the duration of surgery and hospitalization time in the recovery room are not deterministic and it should be taken into account in the planning and scheduling of the ORs [6]. In case, less time is considered in planning than is actually required, the next surgeries cannot be started as scheduled. This results in the tardiness of subsequent surgeries, patient and employee dissatisfaction as well as high overtime costs of ORs for the hospital management. On the other hand, if the reserved time for a surgery is considered more than the real condition, it leads to ORs idleness; the next patient and staff are not ready for the next surgery. Besides, the availability of special equipment required for specific surgeries requires further consideration in their management. Due to the high costs of this equipment, only a limited number are available and must be shared between ORs and different surgeries. Hereafter, they are referred to as Shared Resources. In the case, a surgery needs a shared resource, other surgeries requiring the same must be pending until the present surgery is completed. Consequently, neglecting the use of shared resources in the planning and scheduling of ORs leads to inefficiencies in the daily ORs plan, idleness of the ORs, and overtime costs. The efficient management of ORs consequently requires a highly adaptable solution to account for uncertainties and resource limitations.

In this study, we consider the described OR-scheduling problem and account for different challenges in their management, such as uncertain surgery time in the ORs, uncertain time of hospitalization in the recovery room, and the use of shared resources. In the considered case study, two types of surgeries, including orthopedic surgeries and some general surgeries, share radiology equipment during the procedure. In the case, the surgery time and hospitalized time of each patient cannot be considered as fixed or predetermined. Rather, these are dependent on factors such as the general health condition of the patient, skill of surgeons and OR staff, and the availability of needed equipment. Consequently, we consider surgery time and hospitalized time as uncertain parameters. In different service centers, it is so important to consider the costumers' and managers' preferences, simultaneously. For this purpose, two objective functions are considered, so that the first objective seeks to (minimizing the maximum completion time of surgical operation) minimizes the ORs-related costs. On the other words, the longer an operating room works, the higher the operating costs. Because, the ORs-related costs including, the costs of staff salaries, operating costs of operating room equipment, and the cost of their maintenance and repairing, also reduce by considering the minimizing the maximum completion time of surgical operation. The second objective function (minimizing the sum of tardiness-earliness time) account for patients' satisfaction. For this purpose, a bi-objective robust mixed-integer linear programming model is proposed. A multi-choice goal programming approach with utility function is proposed to cope with the bi-objective model.

The remainder of the study is organized as follows. Section 2 discusses existing studies investigating the ORs scheduling problem. Section 3 provides the problem description, assumptions, and the mathematical model developed for the research problem. The robust counterpart of the mathematical model and multichoice goal programming approach with utility function are also introduced in Section 3. Section 4 represents the computational results to evaluate the performance of the proposed approach and a sensitivity analysis. Finally, Section 5 presents conclusions from the research and future research. 


\section{Literature Review}

Regarding the speed progress of the healthcare industry and the importance of scheduling for the ORs, many studies have been conducted on the scheduling and planning of the ORs in recent years. This section is devoted to reviewing related researches in this context. Azadeh et al. considered how patients in the emergency department are scheduled accounting for their treatment priority. They formulated the problem as a flexible open shop problem and proposed a mixed-integer linear programming model (MILP) and proposed a genetic algorithm to minimize the total waiting time of patients [7]. Lee et al. developed a multiobjective integer linear programming (ILP) model to optimally schedule elective surgeries regarding the availability of ORs and surgeons. The selected objectives functions are minimizing the number of patients waiting for service, underutilization of OR time, maximum expected number of patients in the recovery unit, and expected range of patients in the recovery unit. They developed two goal programming (GP) approaches for this problem [8]. Denton et al. parented a stochastic optimization approach to assign surgeries to the ORs. Objective function seeks to minimize fixed cost of opening ORs and a variable cost of overtime. They proposed a simple heuristic method to solve the problem [9]. Rachuba and Werners considered ORs scheduling regarding the uncertain surgery durations and patients' emergency arrivals. In order to consider different stakeholders' objectives, they proposed a multi-objective robust mixed-integer mathematical model [10]. Jebali and Diabat proposed a two-stage chance-constrained programming model for ORs scheduling account for the uncertain surgery time, random patient length of stay in the ICU, and random reserved resources for the emergency cases. Selected objective function aims to minimize patients' costs, OR utilization costs, and penalty costs for exceeding ICU capacity. They proposed a sample average approximation algorithm (SAA) to solve the model [11].

Liu et al. developed a two-step MILP model and an SAA approach for the ORs scheduling problem in which the surgery time is as an uncertain parameter. The proposed approach seeks to increase resource utilization, reduce the ORs cost, and improve surgeons' satisfaction [12]. Molina-Pariente et al. studied a stochastic OR scheduling problem which minimizes the under- and overtime costs of the ORs and the cost of exceeding the system capacity. They considered different uncertain parameters such as surgeries time, surgeons' capacity, and arrivals of emergency surgeries. They proposed a Monte Carlo optimization-based approach, in which iterative greedy local search method is combined by Monte Carlo simulation [13]. Neyshabouri and Berg studied a two-stage robust optimization model to handle the uncertainty in surgery time and length-of-stay in the surgical ICU. They developed a column-and-constraint generation approach to generate optimal solutions [14]. Liu et al. developed an iterative auction mechanism to maximize the overall social welfare of patients in the ORs scheduling problem. They also took into account the eligibility constraints of the ORs [15]. Kroer et al. developed a stochastic model where surgeries times vary and the emergency patients' arrivals are not deterministic. The proposed approach generates robust ORs schedules that minimize the overtime work and release unused capacity [16]. Koppka et al. dealt with a mathematical model that assigns the ORs available time to enhance the overall performance. The selected objective function maximizes the probability of a perfect day without overtime or cancellations. They considered surgery time and the number of patients in a day as uncertain parameters [17]. Moosavi and Ebrahimnejad proposed a multi-objective mathematical model for upstream and downstream units of ORs. They proposed a robust counterpart of the mathematical model to consider uncertain parameters, including surgery time, emergency demand, and length of stay. They also proposed a MIP-based local search neighborhood approach to solve the problem [18]. Sagnol et al. considered a parallel-machines scheduling problem to formulate the problem of allocating ORs to surgeries, so that surgery time follows a lognormal distribution. They solved the robust counterpart of the proposed model using a cutting-plane approach [19]. Kamran et al. considered patients' allocation to the available OR blocks. They proposed multi-objective two-stage stochastic and two-stage chance-constrained stochastic programming models. They solved the proposed 
models by the SAA approach and Benders decomposition method [20]. Hamid et al. developed a new and comprehensive MILP model to consider inpatient surgeries in ORs scheduling. They developed two metaheuristic algorithms, namely NSGA-II and MOPSO, to achieve the Pareto solutions and the PROMETHEE-II approach is applied to select the best solution among the Pareto solutions [21]. Lin and Chou focused on multifunctional operating rooms in ORs scheduling problem. The selected objective functions are: maximizing ORs utilization, minimizing the overtime cost, and minimizing the wasting cost of unused time. To cope with the problem, they developed some simple heuristic methods, hybrid genetic algorithm, and elite search approach for this problem [22].

Vali-Siar et al. developed an MILP model to plan and schedule ORs with respect to the uncertainty in surgery and recovery duration. They proposed a new heuristic approach to minimize the tardiness in surgeries, over and idle time [23]. Silva and De Souza addressed ORs scheduling problem with comment resources. The considered uncertain surgery times and patients' arrival. They proposed an approximate dynamic programming approach to minimize the total expected cost. The experimental results show that the proposed approach can reduce the total expected cost, significantly [24]. Zhang et al. addressed ORs scheduling problem regarding the downstream resources capacity constraints. They proposed a stochastic programming model, in which surgery duration and length-of-stay are as uncertain parameters. They developed column-generation-based heuristic methods to solve the research problem [25]. Akbarzadeh et al. studied the surgical case in which, operation room planners want to make a balance between the capacity and demand. They developed a three-phase column generation-based heuristic to generate a feasible solution and it improved by local branching [26]. Nasiri et al. proposed a mathematical model to select and assign elective surgeries on a particular day. They proposed a fuzzy robust optimization approach to maximize the number of surgeries using fixed resources, minimize the total fixed and overtime costs of the ORs, and minimize the maximum completion time of ORs [27]. Najjarbashi and Lim proposed a risk-based solution approach for the ORs scheduling problem regarding the Conditional Value-at-Risk (CVaR) concept. They developed a stochastic MILP model to minimize the CVaR of over- and idle time costs [28]. Atighehchian et al. studied ORs scheduling problem concerning uncertain duration of surgeries in a multiresource environment. They presented a two-stage stochastic mixed-integer programming model to minimize the ORs idle and over time [29]. Marchesi et al. proposed a two-stage stochastic programming model with constant recourse to solve ORs staffing and scheduling problem. They developed possible realization scenarios to deal with the demand uncertainty by the SSA algorithm. [30]. Barrera et al. proposed a stochastic dynamic mathematical model for the ORs scheduling problem to minimize the cost of referrals to the private sector. They developed a heuristic approach to achieve near-optimal solutions in a reasonable time [31]. Bovim et al. proposed a two-stage stochastic optimization model combined with a simulationoptimization approach to schedule ORs. They considered arrivals of the emergency patients and surgery duration as uncertain parameters [32]. Khaniyev et al. studied next-day ORs scheduling problem regarding the uncertain surgery durations to minimize the weighted sum of the OR idle and over time and expected patient waiting times. They proposed some simple heuristics motivated by a real situation to find nearoptimal solutions [33]. In order to convince the readers, some of the main researches in the ORs scheduling problem are summarized in Table 1.

Insert Table 1

\section{2-1 Research contributions}

Based on our discussion of the existing research landscape on the topic of ORs scheduling problem, and as is summarized in Table 1, the contributions of the present research are the following. A central contribution 
presented in this study is the consideration of shared resources for ORs scheduling. However, clinical practice highlights the relevance of shared resources as a central constraining factor for surgery planning. Thus, embedding it in the optimization approach adjusts existing models to practical realties faced in hospital management and surgery. As demonstrated in the literature discussion, this crucial aspect is missing in existing methodological approaches. This is of the specific relevance for decision-making concerning critical surgeries in emergencies.

This paper considers two different objective functions for addressing the ORs scheduling problem, including the maximum completion time of the surgical operations and the sum of the tardiness and earliness time. The first objective is of relevance for the hospital management to reduce the maximum completion time and consequently, reduce ORs costs. The second objective concerns patients since both the positive deviation (tardiness) and negative deviation (earliness) from the scheduled surgery affect patient satisfaction as well as corresponding costs. Regarding the literature, a highly regarded approach in the multi-objective ORs scheduling problem is the goal programming approach $[4,8,15]$. In the GP, an aspiration level is defined for each objective function which is determined according to decision-makers' opinions. One of the limitations of utilizing GP to handle multi-objective models is that the preference structure of the decision-makers is not easily considered which is far from reality. Considering utility function can tackle this difficulty. In this study, for the first time, the multi-choice goal programming approach with utility function is used to handle the bi-objective ORs scheduling problem. The key advantage of this approach is the consideration of decision-maker preferences that affect his/her approach to maximize utility.

One of the main concerns in the ORs scheduling problem is uncertainty of the input parameters. There are various approaches to cope with this issue, such as stochastic programming, robust optimization approach, and fuzzy approach. Unlike the stochastic programming, the robust optimization approach does not need any information about the probability distribution of the uncertain data. Due to the nature of the data in the ORs scheduling problem, it is so difficult or impossible to achieve the probability distribution of data in the ORs. Thus, we considered a robust optimization approach in this research. Based on the literature reviewed, robust optimization approach has not been rarely studied in the ORs scheduling problem and Bertsimas and Sim [34] approach has not accrued in the previous researches.

\section{Methods}

\subsection{Problem statement}

Suppose that there are several patients that must be assigned to operating rooms according to a patient allocation matrix. This matrix indicates the allocation of patients to respective surgery rooms and indicates which operating room is equipped for the patient's surgery. Each operating room requires preparation at the beginning of the operation. Accordingly, in between two successive operations, a specific amount of time is allocated to washing and reheating. After surgery, patients are immediately transferred to the recovery room. In this research, some shared resources are considered in a way that if a surgery uses a shared resource, other surgeries cannot use it during the present surgery. According to the problem definition, the following assumptions are made in this research:

- The number of ORs and recovery beds are less than the number of patients. 
- A weight is assigned to each operation which indicates the surgery priority. In this way, the higher the assigned weight to the surgery is, the higher the urgency of the surgery would be.

- There is a time interval for starting a surgery due to the type of surgery and operating rooms limitation.

- Patients should be assigned to the operating rooms according to the allocation matrix.

- Each patient will be transferred to the recovery room immediately after surgery in OR.

- Patients who need shared sources are identified by a shared resource matrix.

\section{3-2 Mathematical model}

In this section, a bi-objective MILP model is presented to schedule the surgeries in the ORs and recovery room. For this purpose, the following notations are used in the model:

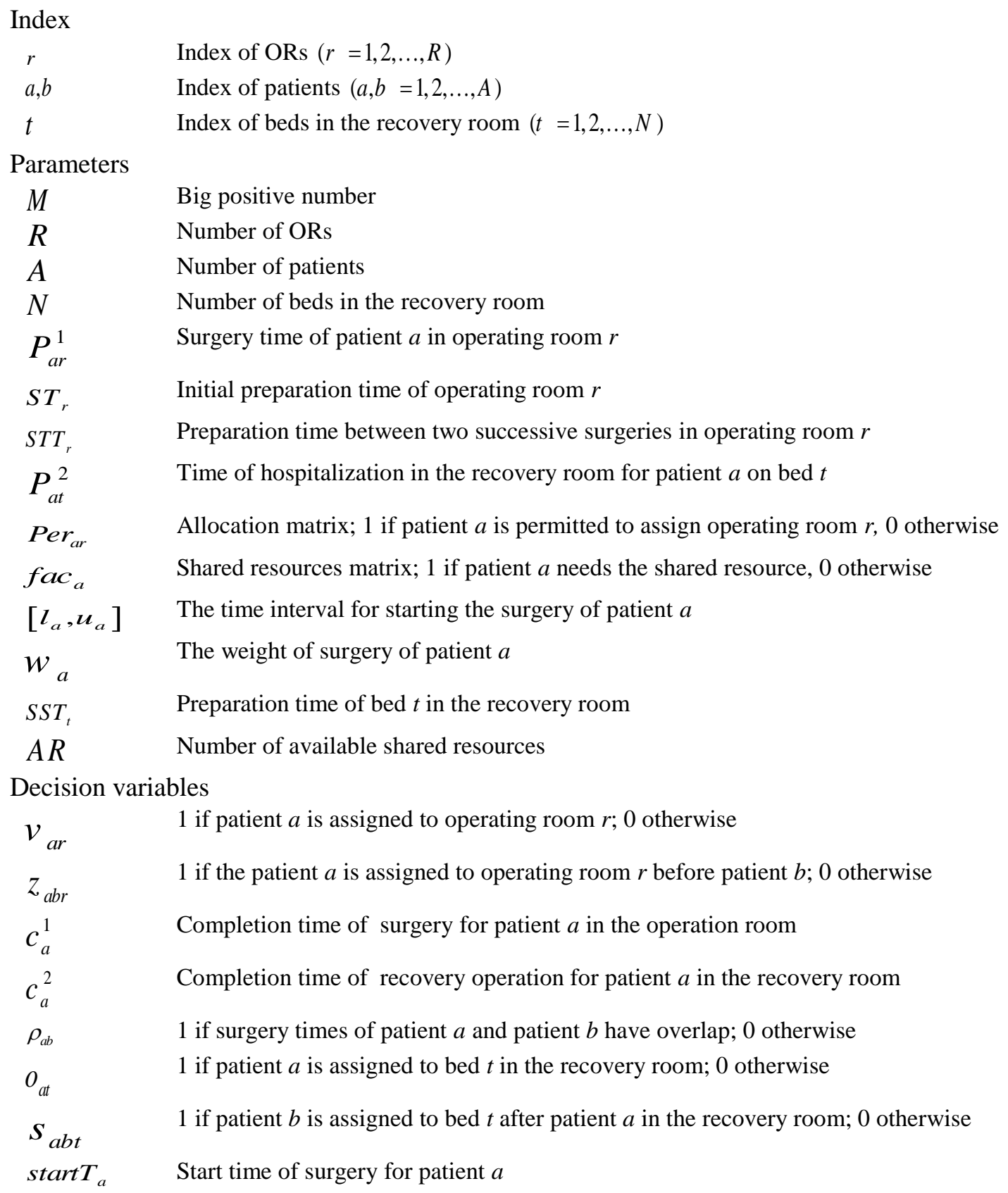



$\boldsymbol{T}_{a} \quad$ Tardiness of surgery for patient $a$
$E_{a} \quad$ Earliness of surgery for patient $a$
$C_{\max } \quad$ Maximum completion time of the surgical operations

In terms of the above notations, the proposed model can be stated as bellow:

$$
\begin{aligned}
& \operatorname{MinZ} Z_{1}=C_{\max } \\
& \operatorname{MinZ} Z_{2}=\sum_{a}^{A} w_{a}\left(T_{a}+E_{a}\right)
\end{aligned}
$$

S.t:

$$
\begin{aligned}
& \sum_{r=1}^{A} v_{a r} . \operatorname{Per}_{a r}=1 \\
& c_{a}^{1} \geq \sum_{r=1}^{R}\left(P_{a r}^{1}+S T_{r}\right) \times v_{a r} \\
& c_{a}^{1}+M\left(2+z_{a b r}-v_{a r}-v_{b r}\right) \geq c_{b}^{1}+\left(P_{a r}^{1} \cdot v_{a r}\right)+\left(S T T_{r} \cdot v_{a r}\right) \quad \begin{array}{l}
a, b=1,2, \ldots, A \& a \neq b \\
r=1,2, \ldots, R
\end{array} \\
& c_{b}^{1}+M\left(3-z_{a b r}-v_{a r}-v_{b r}\right) \geq c_{a}^{1}+\left(P_{b r}^{1} \cdot v_{b r}\right)+\left(S T T_{r} \cdot v_{b r}\right) \quad \begin{array}{l}
a, b=1,2, \ldots, A \& a \neq b \\
r=1,2, \ldots, R
\end{array} \\
& M . \rho_{a b} \geq c_{a}^{1}-\left(c_{b}^{1}-\sum_{r=1}^{R} P_{b r}^{1} \cdot v_{b r}\right) \quad a, b=1,2, \ldots, A \& a \neq b \\
& f a c_{a}+\sum_{b=1}^{A} f a c_{b} \cdot\left(\rho_{a b}+\rho_{b a}-1\right) \leq A R \quad a=1,2, \ldots, A \\
& \sum_{t=1}^{N} o_{a t}=1 \quad a=1,2, \ldots, A \\
& c_{a}^{2}=c_{a}^{1}+\sum_{t=1}^{N} P_{a t}^{2} . o_{a t} \quad a=1,2, \ldots, A \\
& c_{a}^{2}+M \cdot\left(2+s_{a b t}-o_{a t}-o_{b t}\right) \geq c_{b}^{2}+\left(P_{a t}^{2} o_{a t}\right)+\left(S S T_{t} o_{a t}\right) \quad \begin{array}{l}
a, b=1,2, \ldots, A \& a \neq b \\
t=1,2, \ldots, N
\end{array} \\
& c_{b}^{2}+M \cdot\left(3-S_{a b t}-o_{a t}-o_{b t}\right) \geq c^{2}+\left(P_{b t}^{2} o_{b t}\right)+\left(S S T, o_{b t}\right) \quad a, b=1,2, \ldots, A \& a \neq b \\
& v_{a r} \leq \operatorname{Per}_{a r} \\
& t=1,2, \ldots, N \\
& a=1,2, \ldots, A \\
& r=1,2, \ldots, R \\
& a=1,2, \ldots, A \\
& \operatorname{starT}_{a} \geq c_{a}^{1}-\sum_{r=1}^{R} P_{a r}^{1} \cdot v_{a r} \quad a=1,2, \ldots, A \\
& T_{a} \geq \operatorname{star}_{a}-u_{a} \\
& a=1,2, \ldots, A \\
& a=1,2, \ldots, A \\
& a=1,2, \ldots, A \\
& a, b=1,2, \ldots, A \& a \neq b \\
& z_{a b r}, v_{a r}, s_{a b t}, o_{a t}, \rho_{a b} \in\{0,1\} \quad r=1,2, \ldots, R \\
& t=1,2, \ldots, N
\end{aligned}
$$


The first objective function tries to minimize the maximum completion time of the surgical operations and the second objective function minimizes the sum of the earliness and tardiness. Constraint set (3) indicates that each patient must be assigned to one OR regarding the allocation matrix. Constraint set (4) shows the start time of surgery for a patient due to initial preparation time. Constraint sets (5) and (6) represent the relation between the completion times of two successive surgeries. Constraint set (7) is incorporated into the model to show the overlap between surgeries. Constraint set (8) indicates that surgeries requiring the shared resources, should not be done, simultaneously. Constraint set (9) indicates that each patient must be assigned to only one recovery bed. Constraint set (10) shows the relationship between completion time of surgery in the ORs and recovery room. Constraint sets (11) and (12) express the completion times of two successive surgeries in the recovery room. Constraint set (13) prevents the allocation of patients to the unrelated operating rooms. Constraint set (14) shows the linearization of the first objective function and constraint set (15) calculates the start time of the patient's surgery. Constraint sets (16) and (17) calculates tardiness and earliness time and finally, constraint sets (18) and (19) show the type of decision variables.

\section{3-3 Robust optimization approach}

Robust Optimization is one of the new ways in mathematical programming that attracted much attention recently [35]. The main objective of the robust optimization approach is to select solutions that are able to cope with the uncertain data. It is assumed that the uncertain data are bounded but unknown, and in most researches, uncertainty space is convex. Unlike the stochastic programming, the robust optimization approach does not need any information about the probability distribution of the uncertain data. In order to tackle the uncertainty, the optimization problem with uncertainty parameters is transformed into a robust counterpart [36]. During the last years, many researchers tried to develop new and efficient approaches regarding the uncertainty in data. One of the main development in this context is the proposed approach by Bertsimas and Sim [34]. They provided a robust approach for a mathematical model by using the uncertainty budget, so that the main advantage of this approach over other versions of the robust optimization approach is to consider this parameter to control the conservative degree of the solutions. In the robust optimization formulation, $\Gamma_{i} \in\left[0,\left|J_{i}\right|\right]$, as a budget parameter, is inserted into the model, where $\left|J_{i}\right|$ represents the number of uncertain coefficients in constraint set $i$. The proposed methodology ensures that constraints will be satisfied despite changing in data and the protection level does not depend on the solution of the robust model [34]. To develop the robust counterpart of the proposed MILP model, the following parameters and decision variables are considered:

Parameters

$\begin{array}{ll}\Gamma 1_{b} & \text { Uncertainty budget of constraint set (4) } \\ \Gamma 2_{a b r} & \text { Uncertainty budget of constraint sets (5) and (6) } \\ \Gamma 3_{a b} & \text { Uncertainty budget of constraint set (7) } \\ \Gamma 4_{a} & \text { Uncertainty budget of constraint set (10) } \\ \Gamma 5_{a b t} & \text { Uncertainty budget of constraint sets (11) and (12) } \\ \hat{P}_{a r}^{1} & \text { Measure of uncertainty for the surgery time of patient } a \text { in OR } r \\ \hat{P}_{t a}^{2} & \text { Measure of uncertainty for the hospitalization time of patient } a \text { in the recovery room on bed } t \\ D e c i s i o n & \text { variables } \\ G 1_{b}, B e 1_{a r} & \text { Auxiliary dual variables of constraint set (4) } \\ G 2_{a b r}, B e 2_{a r} & \text { Auxiliary dual variables of constraint sets (5) and (6) }\end{array}$


$G 3_{a b}, B e 3_{a r} \quad$ Auxiliary dual variables of constraint set (7)

$D 1_{a}, B 1_{a t}^{2} \quad$ Auxiliary dual variables of constraint set (10)

$D 2_{a b t}, B 2_{a t}^{2} \quad$ Auxiliary dual variables of constraint sets (11) and (12)

It should be noted that the robust counterpart model by Bertsimas and Sim [34] is proposed for inequality constraints. On the other hand, constraint set (10) is an equal equation. By replacing the equal constraint with two less than or equal and greater than or equal constraints, it leads to the model infeasibility. Thus, we applied the proposed approach by Lin et al. [37]. Regarding constraint set (10), in the constraint sets that term $c_{a}^{2}$ exists, it is replaced by $c_{a}^{1}+\sum_{t=1}^{N} P_{a t}^{2} . o_{a t}$. The robust counterpart of the model is as:

$$
\begin{aligned}
& \operatorname{MinZ}_{1}=C_{\text {max }} \\
& \operatorname{MinZ}_{2}=\sum_{a}^{A} w_{a}\left(T_{a}+E_{a}\right)
\end{aligned}
$$

St:

$$
\begin{aligned}
& c_{b}^{1} \geq \sum_{r=1}^{R} P_{b r}^{1} \cdot v_{b r}+G 1_{b} \Gamma 1_{b}+\sum_{r=1}^{R} B e 1_{b r} \cdot v_{b r}+\sum_{r=1}^{R} S T_{r} \cdot v_{b r} \quad b=1,2, \ldots, A \\
& G 1_{b}+B e 1_{b r} \geq \hat{P}_{b r}^{1} v_{b r} \quad \begin{aligned}
b & =1,2, \ldots, A \\
& r=1,2, \ldots, R
\end{aligned} \\
& c_{a}^{1}+M\left(2+z_{a b r}-v_{a r}-v_{b r}\right) \geq c_{b}^{1}+\left(P_{a r}^{1} v_{a r}\right)+\left(S T T_{r}, v_{a r}\right)+\left(G 2_{a b r} . \Gamma 2_{a b r}\right)+B e 2_{a r} \quad a, b=1,2, \ldots, A \& a \neq b \\
& r=1,2, \ldots, R
\end{aligned}
$$

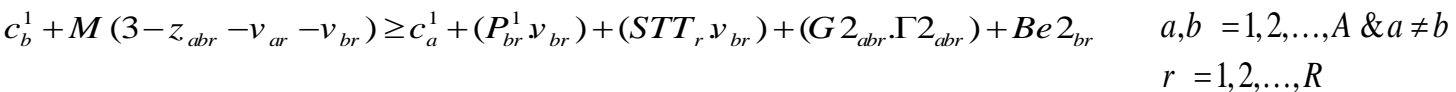

$$
\begin{aligned}
& G 2_{a b r}+B e 2_{b r} \geq \hat{P}_{b r}^{1} v_{b r} \\
& M \cdot \rho_{a b} \geq c_{a}^{1}-\left(c_{b}^{1}-\sum_{r=1}^{R} P_{b r}^{1} \cdot v_{b r}-G 3_{a b} \cdot \Gamma 3_{a b}-\sum_{r=1}^{R} B e 3_{b r} \cdot v_{b r}\right) \\
& G 3_{a b}+B e 3_{b r} \geq \hat{P}_{b r}^{1} \cdot v_{b r} \\
& c_{a}^{2}+M .\left(2+s_{a b t}-o_{a t}-o_{b t}\right) \geq\left(c_{b}^{2}+\sum_{t=1}^{N} P_{a t}^{2} . o_{a t}+\left(D 1_{a} \cdot \Gamma 4_{a}\right)+\sum_{t=1}^{N} B 1_{a t}^{2} o_{a t}\right) \\
& +\left(P_{a t}^{2} \cdot o_{a t}\right)+\left(S S T_{t} \cdot o_{a t}\right)+\left(D 2_{a b t} \cdot \Gamma 5_{a b t}\right)+B 2_{a t}^{2} \\
& c_{b}^{2}+M \cdot\left(3-s_{a b t}-o_{a t}-o_{b t}\right) \geq\left(c_{a}^{1}+\sum_{t=1}^{N} P_{a t}^{2} \cdot o_{a t}+\left(D 1_{a} \cdot \Gamma 4_{a}\right)+\sum_{t=1}^{N} B 1_{a t}^{2} \cdot o_{a t}\right) \quad \begin{array}{l}
a, b=1,2, \ldots, A \& a \neq b \\
t=1,2, \ldots, N
\end{array} \\
& +\left(P_{b t}^{2} \cdot o_{b t}\right)+\left(S S T_{t} \cdot o_{b t}\right)+\left(D 2_{a b t} . \Gamma 5_{a b t}\right)+B 2_{b t}^{2} \\
& D 1_{a}+B 1_{a t}^{2} \geq \hat{P}_{a t}^{2} . o_{a t} \\
& D 2_{a b t}+B 2_{b t}^{2} \geq \hat{P}_{b t}^{2} \cdot o_{b t} \\
& G 1_{b}, G 2_{a b r}, G 3_{a b}, D 1_{a}, D 2_{a b t} \geq 0 \\
& B e 1_{a r}, B e 2_{a r}, B e 3_{a r}, B 1_{a t}^{2}, B 2_{a t}^{2} \geq 0
\end{aligned}
$$


and constraint sets (3),(8),(9),(13)-(19)

\section{3-4 Multi-choice goal programming (MCGP) with utility function}

Goal programming approach is one of the highly regarded approaches to tackle multi-objective optimization models. It seeks to minimize unfavorable deviations of the objective functions from the goals. GP seeks to minimize the sum of the deviations from the expectation (anticipation) level for the objective functions [38]. In this paper, the multi-choice goal programming (MCGP) approach considering utility function is applied to tackle the proposed model. In the classic GP approach, it is necessary to define an aspiration level for each objective function with respect to decision maker's opinion. On the other side, his/her preference structure is not considered easily and may be far from reality. Thus, Chang [39] defined utility function to incorporate the decision maker's preference values into the model. One of the main advantages of the MCGP with utility function rather than other versions of GP is to consider the decision maker's preference value in which decision maker attempts to optimize her/his expected utility [40]. In order to present the mathematical model, the following parameters and decision variables are considered:

Parameters

$$
\begin{array}{ll}
{\left[U_{k, \min }, U_{k, \max }\right]} & \begin{array}{l}
\text { The range of kth aspiration level } \\
\beta_{k}^{d}
\end{array} \\
\beta_{k}^{\delta} & \text { The weight of normalized deviation } \\
& \text { The weight of positive and negative deviations }
\end{array}
$$

Decision variables

$\begin{array}{ll}y_{k} & \text { The continuous decision variable } \\ d_{k}^{+} & \text {The positive deviations of } f_{k}(X) \text { from } y_{k} \\ d_{k}^{-} & \text {The negative deviations of } f_{k}(X) \text { from } y_{k} \\ \delta_{k}^{-} & \text {The normalized deviation of } y_{k} \text { from } U_{k, \text { min }} \\ \lambda_{k} & \text { The utility value }\end{array}$

The proposed model is presented as bellow:

$$
\operatorname{Min} \sum_{k}\left[\beta_{k}^{d}\left(d_{k}^{+}+d_{k}^{-}\right)+\beta_{k}^{\delta} \delta_{k}^{-}\right]
$$

S.t.

$\lambda \leq \frac{U_{k, \max }-y_{k}}{U_{k, \max }-U_{k, \text { min }}}$

$f_{k}(X)+d_{k}^{-}-d_{k}^{+}=y_{k}$

$\lambda_{k}+\delta_{k}^{-}=1$

$U_{k, \min } \leq y_{k} \leq U_{k, \max }$

$d_{k}^{-} \cdot d_{k}^{+}=0$

$d_{k}^{-}, d_{k}^{+}, \delta_{k}^{-}, \lambda_{k} \geq 0$

Model constraint sets

As results, the MCGP with utility function for the proposed robust model is as:

$$
\operatorname{Min} \beta_{1}^{d}\left(d_{1}^{+}+d_{1}^{-}\right)+\beta_{2}^{d}\left(d_{2}^{-}+d_{2}^{+}\right)+\beta_{1}^{\delta} \delta_{1}^{-}+\beta_{2}^{\delta} \delta_{2}^{-}
$$

\section{S.t:}




$$
\begin{aligned}
& \lambda_{1} \leq \frac{C_{\max }^{+}-C_{\max }^{\prime}}{C_{\max }^{+}-C_{\max }^{-}} \\
& \lambda_{2} \leq \frac{E T^{+}-E T^{\prime}}{E T^{+}-E T^{-}} \\
& C_{\max }+d_{1}^{-}-d_{1}^{+}=C_{\max }^{\prime} \\
& \sum_{a=1}^{A} w_{a}\left(T_{a}+E_{a}\right)+d_{2}^{-}-d_{2}^{+}=E T^{\prime} \\
& \lambda_{1}+\delta_{1}^{-}=1 \\
& \lambda_{2}+\delta_{2}^{-}=1 \\
& C_{\max }^{-} \leq C_{\max }^{\prime} \leq C_{\max }^{+} \\
& E T^{-} \leq E T^{\prime} \leq E T^{+} \\
& \text {and constraint sets (3),(8),(9),(13)-(31). }
\end{aligned}
$$

\section{Results and discussion}

This section examines the quality of the mathematical model and the solution approach presented for the ORs scheduling problem. Section 4-1 introduces 36 random test-problems to evaluate the performance of the robust MILP model and analyze the obtained results. Then, a real case study is presented and the quality of the proposed approach is analyzed by real data in section 4-2. Finally, sensitivity analysis is conducted regarding the different parameters of the research problem.

\section{4-1 Random test problems}

This section aims to investigate the performance of the proposed approach regarding random test problems. 36 test problems have generated and four characteristics with different levels are used to typify the test problems. It should be noted that the proposed model is solved by GAMS24 software in i7, $2.67 \mathrm{GHz}, 6$ GB RAM PC. Test problems characteristics are summarized in Table 2.

Insert Table 2

To solve the test problems through MCGP approach with utility function, three steps have been considered as follows:

1. Negative ideal point of the maximum completion time and positive ideal point of the sum of the earliness-tardiness of the surgeries are calculated so that the objective is to minimize the maximum completion time of the surgeries and the sum of the earliness-tardiness of the surgical operations time is considered as a constraint.

2. Positive ideal point of maximum of completion time and negative ideal point of the sum of the earliness-tardiness of the surgeries is calculated so that the objective is to minimize the sum of the earliness-tardiness of the surgeries and maximum completion time of the surgeries is considered as a constraint.

3. Regarding the negative and positive ideal points of the objective functions in these two steps, the MCGP problem with utility function is solved and the final solution is obtained.

In order to solve the test problems, three levels of the uncertainty in surgeries times and hospitalized times in the recovery room have been considered. The obtained results are summarized in Table 3.

\section{Insert Table 3}


In order to analyze the obtained results in Table 3, the gap between the objective functions and the ideal negative value are considered regarding the different characteristics of the test problems.

Figure 1 shows the gap between the objective functions and the ideal negative values regarding the number of patients and uncertainty levels.

\section{Insert Figure 1}

As can be seen, by increasing the number of patients, the gap for $C_{\max }$ objective function is generally decreasing. On the other side, when the number of patients increases to higher levels, we can see a general increasing trend in the gap of $E T$ objective function.

Figure 2 depicts the gap between the objective functions and the ideal negative values according to the shared resources and uncertainty levels.

\section{Insert Figure 2}

With respect to the different values of the number of shared resources, the gap for $C_{\max }$ objective function is generally constant. In the $E T$ objective function, the gap generally narrows by increasing the number of shared resources.

Figure 3 represents the gap between the objective functions and the ideal negative values regarding the number of beds in the recovery room and uncertainty levels.

\section{Insert Figure 3}

According to Figure 3, there is no general trend with respect to the number of beds in the recovery room. On the other side, the average gap for $E T$ objective function is almost constant for different values of the number of beds in the recovery room.

Finally, Figure 4 also represents the gap between the objective functions and the ideal negative values regarding the number of ORs and uncertainty levels.

\section{Insert Figure 4}

As can be seen in Figure 4, the gap for both objective functions is narrowing when the number of ORs decreases.

\section{4-2 Case study}

\section{4-2-1 Description and data}

In order to access the approach, a real-world case study is provided in this article. Shahid Beheshti hospital is a public hospital in Babol, in the north of Iran that was established in 1974. The OR unit has 9 operating rooms and is organized on two floors. The types of surgeries on each floor are presented in Table 4 . The 
OR unit is ready to perform the surgeries from Saturday to Wednesday and Thursday is dedicated to cleaning operations of the ORs and emergency services. The recovery room in this hospital has 7 beds.

Insert Table 4

The OR allocation is only considered in non-emergency conditions and in emergency conditions, the first empty OR is allocated to the emergency case. The working hours of the OR unit are divided into three working shifts: morning, evening, and night. In this hospital, there is no waiting list and the surgeries are performed according to defined prioritization which is presented in Table 5. A special weight is given to each patient in the interval of $[0,1]$ that indicates the patient's priority for surgery.

Insert Table 5

Every patient is transferred to the waiting room to perform the surgeries. In the waiting room, patient's hospitalization records are checked and he/she is prepared for the surgery. Afterward, the patient is transferred to the assigned operation room. After completion of the surgery process, the patient is immediately transferred to the recovery room to reach a stable condition. Finally, the patient is transferred to the ICU or general unit, depending on the patient's general condition.

Before the first surgery, between two subsequent surgeries, and after the last surgery, some preparation and cleaning operations must be done. The ORs equipment preparation and sterilization initially require about 45-60 minutes on average. Also, between two successive surgeries, it takes about 10-25 minutes and after the last surgery, it needs about 45-60 minutes to perform cleaning operations on average. As mentioned before, the surgery and hospitalization times in the recovery room are considered as uncertain parameters. Regarding the data from our case study, minimum and maximum times are presented in Table 6.

Insert Table 6

In the OR unit of the Shahid Beheshti hospital, radiology equipment is a shared source for orthopedic surgeries and some general surgeries. Due to budget limitation, only one radiology equipment is available and the surgeries that require this equipment cannot be performed, simultaneously.

\section{4-2-2 Results}

In order to compare the proposed approach with the current approach and to show the superiority of the proposed approach, real data of five different days are gathered from the ORs of Shahid Beheshti hospital. It is necessary to mention that, regarding the real and fixed data from the case study, uncertainty budgets ( $\Gamma_{1}$ and $\Gamma_{2}$ ) are equal to 0 . As a result, according to the solution obtained by the MCGP method, values of the first and second objective functions are presented in Table 7.

Insert Table 7

According to the data is summarized in Table 7, we can see an improvement about $10.28 \%$ in the first objective function and $10.04 \%$ in the second objective function. Thus, the obtained results show the superiority of the proposed approach to solve the research problem. Besides, we statistically compared the proposed approach with current approach in 95\% confidence interval. Test of hypotheses are as: 


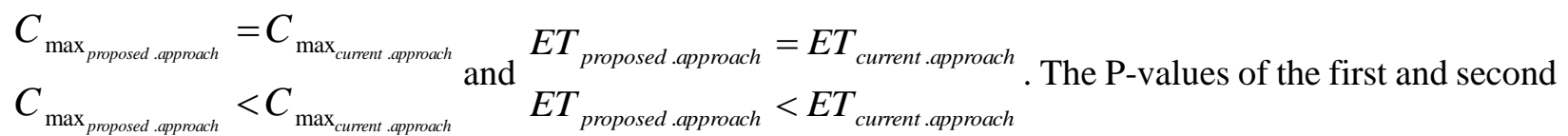

tests are 0.098 and $0.404 . H_{0}$ is rejected in both tests and it shows that the proposed approach outperforms the current approach, statistically.

\section{4-2-3 Sensitivity analysis}

In this section, a sensitivity analysis is conducted to take the influence of each parameter on the obtained results into account. For this purpose, two important parameters, the number of shared resources and a new policy to assigning the surgeries to the ORs, are considered here. Table 8 shows the different situations of sensitivity analysis.

\section{Insert Table 8}

As can be seen, case 1 is related to the basic model and cases 2 and 3 show the number of shared resources. Finally, cases 4 and 5 take into account different policies in assigning the surgeries to the ORs.

\section{Sensitivity analysis of the number of shared resources}

This section is devoted to evaluating the effect of the number of shared resources on both objective functions. For this purpose, in addition to the base case, we consider two new values of 2 and 3 for the number of the shared resources. The obtained results can be seen in Table 9.

Insert Table 9

Regarding Table 9, the shared resource is a bottleneck to enhance the productivity of the ORs regarding the selected objective functions. By increasing the number of shared resources to 2 and 3 , the value of $C_{\max }$ is reduced about $-32.5 \%$ and $-42.7 \%$, respectively. This conclusion is also true for the second objective function, so that we can see a decrease in ET about $-2 \%$ and $-27.9 \%$ with respect to the base case.

\section{Sensitivity analysis on the ORs assigning policy}

In order to conduct a sensitivity analysis on the ORs assigning policy, two different policies are taken into account as follows:

- First policy: In this policy, patients who have surgery time below 60 minutes are allowed to be assigned to the other ORs (only ORs that can perform this surgery).

- Second policy: In this policy, a lower work-load OR is accessible to all patients who need to go to the higher work-load ORs.

Insert Table 10

Regarding Table 10, both proposed policies enhance the performance of the ORs schedule. The first policy is more effective than the second policy with respect to $C_{\max }$ objective function. On the other side, there is no significant difference between the two policies regarding the $E T$.

\section{Conclusion}

In this study, operating rooms (ORs) scheduling problem is considered regarding the shared resources, uncertainty in surgery time, and time of hospitalization in beds in the recovery room. For this purpose, a bi-objective robust mixed-integer linear programming model is proposed. The first objective function tries 
to minimize the maximum completion time of the surgical operations, and the second objective function minimizes the sum of the earliness-tardiness of the surgical operations. In order to solve the proposed model, we used the multi-choice goal programming (MCGP) approach with utility function by utilizing random test problems and real data from Shahid Beheshti hospital, Babol, Iran. Also, a sensitivity analysis regarding some parameters has been conducted. The results demonstrated the superiority of the proposed method for solving the operating rooms scheduling problem.

For future research, we can set up a surgical team and consider all working shifts and relative costs of each surgery. The emergency cases can also be considered in the ORs scheduling problem. In order to solve the problem, we can develop exact approaches such as Branch and Bound method, Bender decomposition algorithm, or Lagrangian relaxation algorithms.

\section{References}

1. Cardoen, B., Demeulemeester, E., Beliën, J. "Operating room planning and scheduling: A literature review”, Eur. J. Oper Res., 201, pp. 921-932 (2010).

2. Abedini, A., Lia, W., Ye, H. "An optimization model for operating room scheduling to reduce blocking across the perioperative process", Procedia Manuf., 10, pp. 60-70 (2017).

3. Rath, S., Rajaram, K., Mahajan, A. "Integrated Anesthesiologist and Room Scheduling for Surgeries: Methodology and Application”, Oper Res., 65, pp. 1-19 (2017).

4. Cappanera, P., Visintin, F., Banditori, C. "A Goal-Programming Approach to the Master Surgical Scheduling Problem", Health Care Systems Engineering for Scientists and Practitioners., Springer Proceedings in Mathematics \& Statistics., 169, pp. 155-166 (2016).

5. Oostrum, J.M.V., Houdenhoven, M.V., Hurink, J.L., et al. "A master surgical scheduling approach for cyclic scheduling in operating room departments", OR Spectrum., 30, pp. 355-374 (2008).

6. Hooshmand, F., MirHassani, S.A., Akhvein, A. "Adapting GA to solve a novel model for operating room scheduling problem with endogenous uncertainty”, Oper Res. Health Care., 19, pp. 26-43 (2018).

7. Azadeh, A., , Farahani, M.H., Torabzadeh, M., et al. "Scheduling prioritized patients in pmergency department laboratories", Comput Meth Prog Bio., 117, pp. 61-70 (2014).

8. Li, X., Rafaliya, N., Baki, M.F., et al. "Scheduling elective surgeries: the tradeoff among bed capacity, waiting patients and operating room utilization using goal programming", Health Care Manag Sci., 20, pp. 33-54 (2015).

9. Denton, B.T., Millner, A.J., Balasubramanian, J., et al. "Optimal allocation of surgery blocks to operating rooms under uncertainty", Oper. Res., 58, pp. 802-816 (2010).

10. Rachuba, S., Werners, B. "A fuzzy multi-criteria approach for robust operating room schedules", Ann Oper Res., 251, pp. 325-350 (2017).

11. Jebali, A., Diabat, A. "A Chance-constrained operating room planning with elective and emergency cases under downstream capacity constraints", Comput. Ind. Eng., 144, pp. 329-344 (2017).

12. Liu, H., Zhang, T., Luo, S., et al. "Operating room scheduling and surgeon assignment problem under surgery durations uncertainty”, Technol. Health Care., 26, pp. 297-304 (2017).

13. Molina-Pariente, J. M., Hans, E.W., Framinan, J.M. "A stochastic approach for solving the operating room scheduling problem", Flex Serv Manuf J., 30, pp. 224-251 (2018).

14. Neyshabouria, S., Berg, B. "Two-stage robust optimization approach to elective surgery and downstream capacity planning", Eur. J. Oper. Res., 260, pp. 21-40 (2016).

15. Liu, L., Wang, C., Wang, J. "A combinatorial auction mechanism for surgical scheduling considering surgeon's private availability information”, J. Comb. Optim., 37, pp. $405-417$ (2018). 
16. Ravnskjær Kroer, L., Foverskov, K., Vilhelmsen, C., et al. "Planning and scheduling operating rooms for elective and emergency surgeries with uncertain duration", Oper. Res. Health Care., 19, pp.107-119 (2018).

17. Koppka, L., Wiesche, L., Schacht, M., et al. "Optimal distribution of operating hours over operating rooms using probabilities”, Eur. J. Oper. Res., 267, pp. 1156-1171 (2018).

18. Moosavi, A., Ebrahimnejad, S. "Scheduling of elective patients considering upstream and downstream units and emergency demand using robust optimization", Comput. Ind. Eng., 120, pp.216-233 (2018).

19. Sagnol, G., Barner, C., Borndörfer, R., et al. "Robust allocation of operating rooms: A cutting plane approach to handle lognormal case durations", Eur. J. Oper Res., 271, pp. 420-435 (2018).

20. Kamran, M. A., Karimi, B., Dellaert, N. "Uncertainty in Advance Scheduling Problem in Operating Room Planning”, Comput. Ind. Eng., 126, pp. 252-268 (2018).

21. Hamid, M., Nasiri, M.M., Werner, F., et al. "Operating room scheduling by considering the decisionmaking styles of surgical team members: a comprehensive approach", Comput. Oper Res., 108, pp. 166181 (2019).

22. Lin, Y.K., Chou, Y.Y. "A hybrid genetic algorithm for operating room scheduling", Health Care Manag. Sci., 23, pp.1-15 (2019).

23. Vali-Siar, M. M., Gholami, S., Ramezanian, R. "Multi-period and multi-resource operating room scheduling under uncertainty: A case study”, Comput. Ind. Eng., 126, pp. 549-568 (2018).

24. Silva, T.A.O., de Souza, M. C. "Surgical scheduling under uncertainty by approximate dynamic programming”, Omega., 95, pp. 12-28 (2020).

25. Zhang, J., Dridi, M., Moudni, A.E. "Column-generation-based heuristic approaches to stochastic surgery scheduling with downstream capacity constraints", Int. J. Prod. Econ., 229, pp.33-47 (2020).

26. Akbarzadeh, B., Moslehi, G., Reisi-Nafchi, M., et al. "The re-planning and scheduling of surgical cases in the operating room department after block release time with resource rescheduling", Eur. J. Oper Res., 278, pp. 596-614 (2019).

27. Nasiri, M.M., Shakouhi, F., Jolai, F. “A fuzzy robust stochastic mathematical programming approach for multi-objective scheduling of the surgical cases", OPSEARCH., 56, pp. 1-21 (2019).

28. Najjarbashi, A., Lim, G. J. "A variability reduction method for the operating room scheduling problem under uncertainty using CVaR", Oper. Res. Health Care., 20, pp. 25-32 (2019).

29. Atighehchian, A., Sepehri, M. M., Shadpour, P., et al. "A two step stochastic approach for operating rooms scheduling in multi resource environment”, Ann. Oper. Res., 292, pp. 191-214 (2019).

30. Marchesi, J. F., Hamacher, S., Fleck, J. L. "A Stochastic Programming Approach to the Physician Staffing and Scheduling Problem", Comput. Ind. Eng., 142, pp. 23-37 (2020).

31. Barrera, J., Carrasco, R. A., Mondschein, S., et al. "Operating room scheduling under waiting time constraints: the Chilean GES plan", Ann. Oper. Res., 286, pp. 501-527 (2020).

32. Bovim, T. R., Christiansen, M., Gullhav, A.N., et al. "Stochastic Master Surgery Scheduling", Eur. J. Oper. Res., 258, pp. 695-711 (2020).

33. Khaniyev, T., Kayis, E., Gullu, R. "Next-Day Operating Room Scheduling with Uncertain Surgery Durations: Exact Analysis and Heuristics", Eur. J. Oper. Res., 286, pp. 49-62 (2020).

34. Bertsimas, D., Sim, M. "The price of robustness", Oper Res., 50, pp. 35-53 (2004).

35. Pouriani, S., Asadi-Gangraj, E., Paydar, M.M. "A robust bi-level optimization modelling approach for municipal solid waste management; a real case study of Iran", J. Clean. Prod., 240, pp. 41-58 (2019).

36. Li, Z., Ierapetritou, M. "Robust Optimization for Process Scheduling Under Uncertainty", Ind. Eng. Chem. Res., 47, pp. 4148-4157 (2008).

37. Lin, X., Janak, S., Floudas,C. "A new robust optimization approach for scheduling under uncertainty: I. Bounded uncertainty”, Comput. Chem. Eng., 28, pp. 1069-1085 (2004). 
38. Charns, A., Cooper,W.W. "Goal programming and multiple objective optimization”, Eur. J. Oper Res., 1, pp. 39-54 (1977).

39. Chang, C. "Multi-choice goal programming with utility functions" Eur. J. Oper Res., 215, pp. 439-445 (2011).

40. Nayeri, S., Asadi-Gangraj, E., Emami, S. "Goal programming-based post-disaster decision making for allocation and scheduling the rescue units in natural disaster with time-window", Int. J. Ind. Eng. Prod. Res., 29, pp. 65-7 (2018). 


\section{Biographies}

Soheil Hasannia-Kolagar received his BS degree in Industrial Engineering from Mazandaran University of Science and Technology and MS degree in Industrial Engineering from Babol Noshirvani University of Technology, Babol, Iran. His research interests include operations research, sequencing and scheduling, and healthcare systems.

Ebrahim Asadi-Gangraj received his BS degree in Industrial Engineering from Isfahan University of Technology, Iran, in 2005, and MS and PhD degrees in Industrial Engineering from Tarbiat Modares University, in 2008 and 2014, respectively. He is currently Assistant Professor of Industrial Engineering at Babol Noshirvani University of Technology, Babol, Iran. His research interests include applied operations research, sequencing and scheduling, production planning, and supply chain management. He has published articles in journals such as Applied Mathematical Modelling, Neural Computing and Applications, Computers and Idustrial Engineering, Soft Computing, and etc.

Mohammad Mahdi Paydar is an Associate Professor in the Department of Industrial Engineering at the Babol Noshirvani University of Technology, in Babol, Iran. He received his Ph.D. in Industrial Engineering from Iran University of Science and Technology in 2014. His research interests include supply chain design, applied operations research, multi-objective optimization, and cellular manufacturing. He has published more than 90 papers in international journals and conferences including Tourism Management, Expert Systems with Applications, Computers \& Operations Research, Journal of Cleaner Production, Computers \& Industrial Engineering, Knowledge-Based Systems, Scientia Iranica, Applied Mathematical Modelling, etc.

Novin Nikbakhsh is an Associate Professor in the Department of Surgery, Faculty of Medicine, Babol University of Medical Sciences at the Babol University of Medical Sciences, in Babol, Iran. He has published in journals such as International Journal of Molecular and Cellular Medicine, Journal of Cell Communication and Signaling, Spectrochimica Acta Part A: Molecular and Biomolecular Spectroscopy, etc. 


\section{Figure Captions}

Figure 1: The Gap between the objective functions and the ideal negative values regarding the number of patients

Figure 2: The Gap between the objective functions and the ideal negative values regarding the number of shared resources

Figure 3: The Gap between the objective functions and the ideal negative values regarding the number of beds in the recovery room

Figure 4: The Gap between the objective functions and the ideal negative values regarding the number of ORs 


\section{Table Captions}

Table 1: Categorization of the related research

Table 2: Test problems characteristics of the random test problems

Table 3: Results of the test problems

Table 4: Types of surgeries on each floor

Table 5: Prioritization of patients in the OR unit

Table 6: Minimum and maximum times for different surgeries and the recovery room (minute)

Table 7: Results of the case study

Table 8: Different situations of sensitivity analysis

Table 9: Sensitivity analysis of the number of shared resources

Table 10: Sensitivity analysis of the ORs assigning policy 
Figure 1

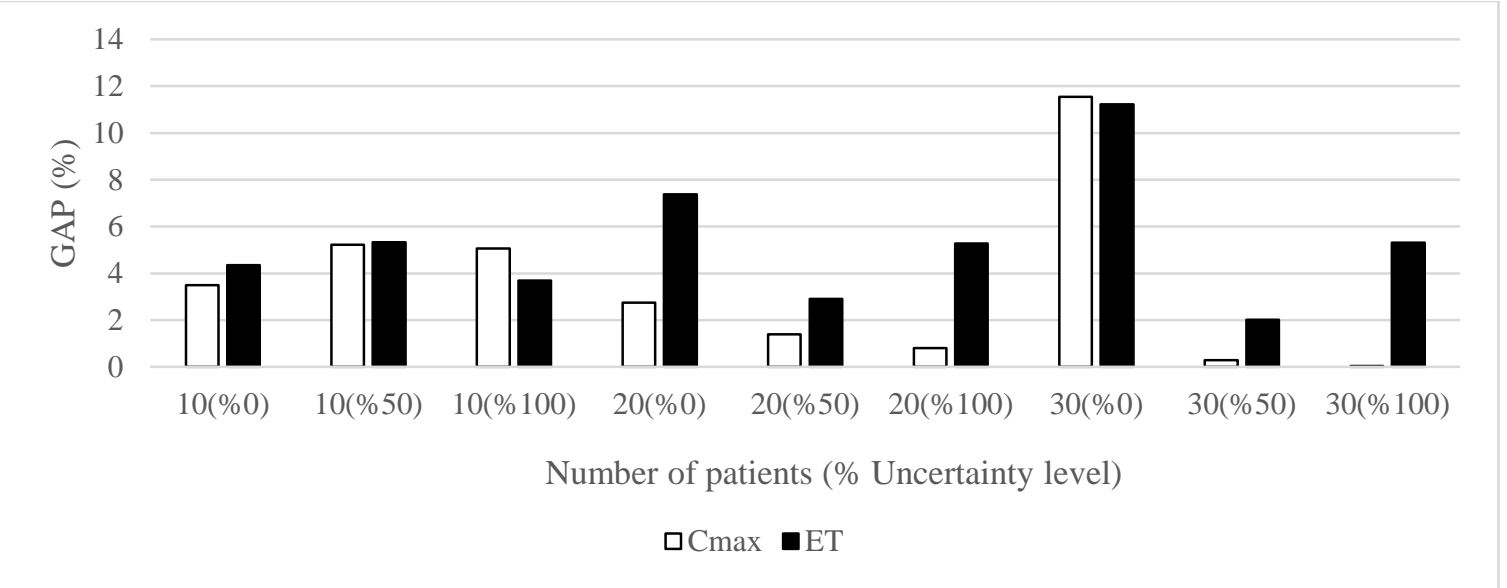


Figure 2

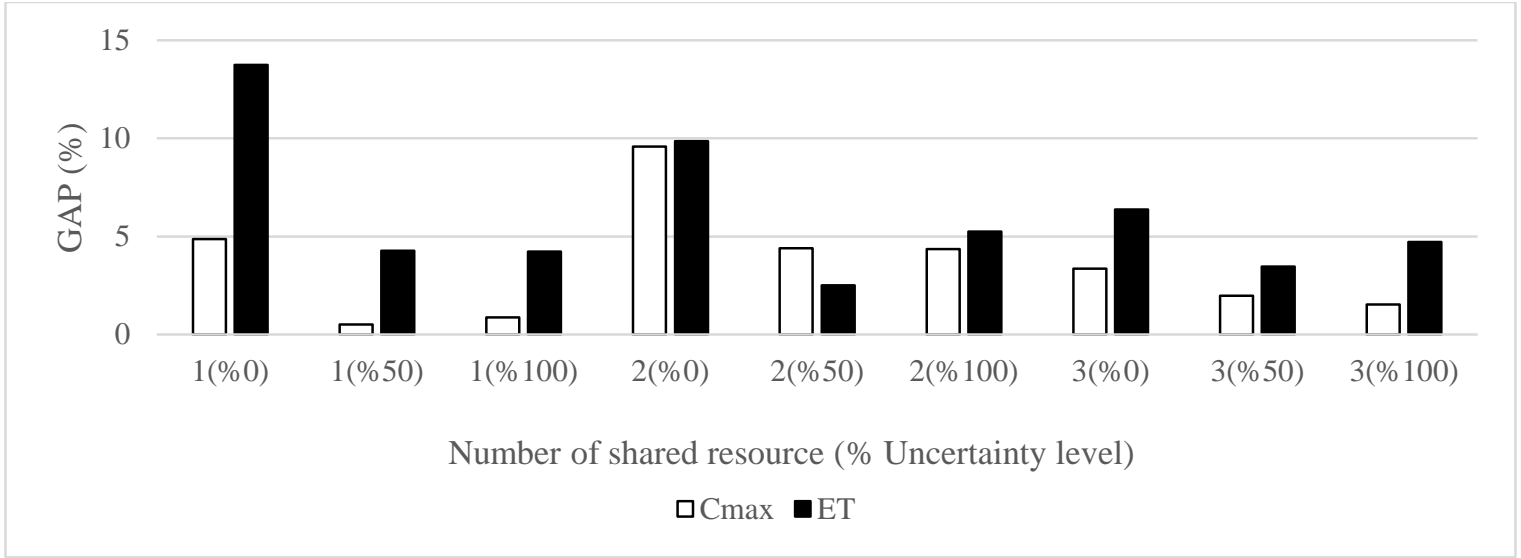


Figure 3

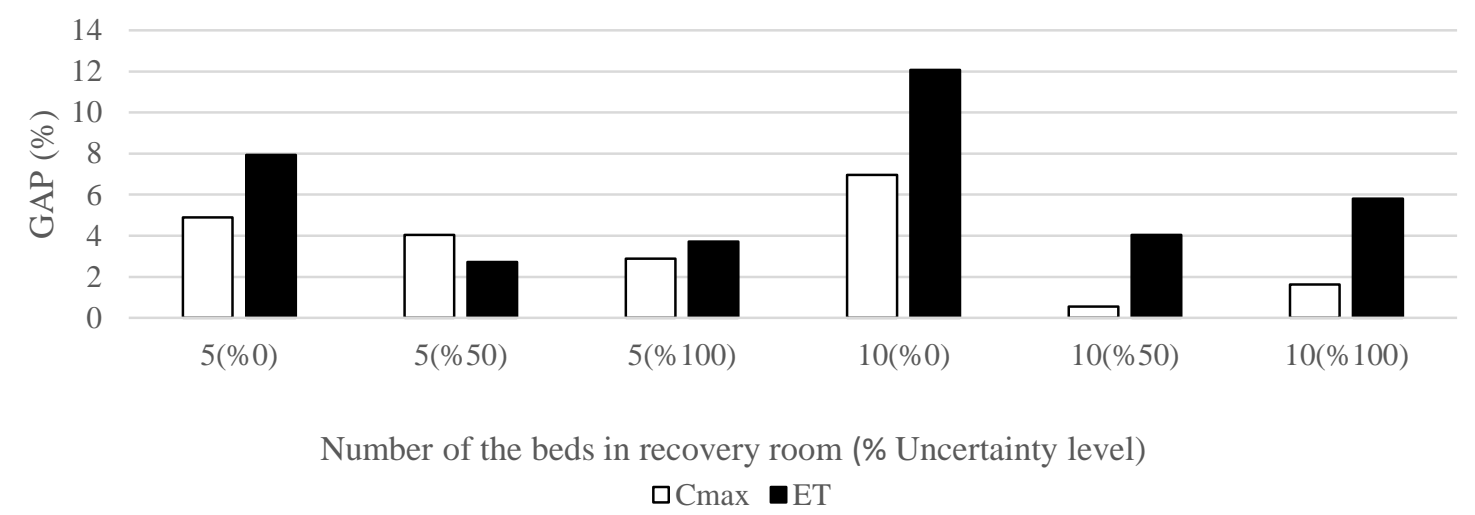


Figure 4

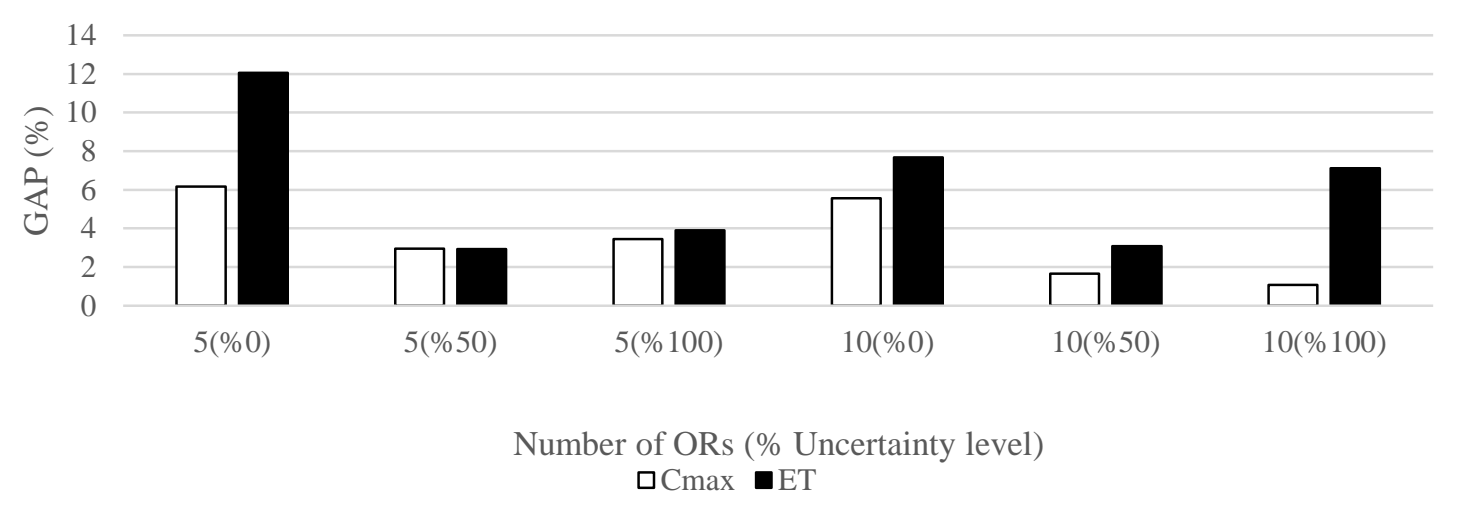


Table 1

\begin{tabular}{|c|c|c|c|c|c|}
\hline Author(s) & Year & Objective function(s) & Uncertainty & $\begin{array}{c}\text { Shared } \\
\text { resources }\end{array}$ & Solving method \\
\hline Latore et al. & 2016 & Minimize the closing time of the last OR & & & $\begin{array}{l}\text { Genetic Algorithm } \\
\text { (GA) }\end{array}$ \\
\hline $\begin{array}{l}\text { Rachuba and } \\
\text { Werners }\end{array}$ & 2017 & $\begin{array}{l}\text { Minimize waiting time, staff overtime, and the } \\
\text { number of deferrals }\end{array}$ & $\begin{array}{l}\text { Robust mixed-integer } \\
\text { programming }\end{array}$ & & $\begin{array}{l}\text { Multi-objective robust } \\
\text { mixed-integer } \\
\text { mathematical model }\end{array}$ \\
\hline Liu et al. & 2017 & $\begin{array}{l}\text { Maximize the social welfare of patients, Maximize } \\
\text { surgeons' preference values, and Minimize the } \\
\text { revelation of surgeons' private information }\end{array}$ & $\begin{array}{l}\text { Stochastic mixed- } \\
\text { integer programming }\end{array}$ & & $\begin{array}{c}\text { Sample Average } \\
\text { Approximation (SAA) } \\
\text { algorithm }\end{array}$ \\
\hline $\begin{array}{l}\text { Neyshabouri } \\
\text { \& Berg }\end{array}$ & 2017 & Minimize total costs & $\begin{array}{c}\text { Two-stage robust } \\
\text { optimization }\end{array}$ & & $\begin{array}{l}\text { Column-and-constraint } \\
\text { generation method }\end{array}$ \\
\hline $\begin{array}{l}\text { Molina- } \\
\text { Pariente et al. }\end{array}$ & 2018 & $\begin{array}{l}\text { Minimize the total expected cost of the surgical } \\
\text { resources }\end{array}$ & $\begin{array}{l}\text { Stochastic mixed- } \\
\text { integer programming }\end{array}$ & & $\begin{array}{c}\text { Monte Carlo } \\
\text { simulation \& Iterative } \\
\text { greedy local search } \\
\text { method }\end{array}$ \\
\hline Sagnol et al. & 2018 & Minimize the fixed cost and the overtime cost & $\begin{array}{l}\text { Robust optimization } \\
\text { approach }\end{array}$ & & Exact solution methods \\
\hline Kamran et al. & 2018 & $\begin{array}{l}\text { Minimize waiting time of patients, tardiness, } \\
\text { cancellation, block overtime, and the number of } \\
\text { surgery days of surgeons }\end{array}$ & $\begin{array}{l}\text { Two-stage stochastic } \\
\text { programming \& Two- } \\
\text { stage chance- } \\
\text { constrained stochastic } \\
\text { programming }\end{array}$ & & $\begin{array}{l}\text { SAA \& Benders } \\
\text { Decomposition }\end{array}$ \\
\hline Nasiri et al. & 2019 & $\begin{array}{l}\text { Maximize the number of surgeries, Minimize the total } \\
\text { fixed and overtime costs, and the maximum of } \\
\text { completion time of ORs }\end{array}$ & $\begin{array}{l}\text { Fuzzy robust } \\
\text { optimization }\end{array}$ & & $\begin{array}{c}\text { Multi-objective goal } \\
\text { programming approach } \\
\text { (MOGP) }\end{array}$ \\
\hline $\begin{array}{l}\text { Najjarbashi \& } \\
\text { Lim }\end{array}$ & 2019 & Minimize the CVR of over and idle time costs & $\begin{array}{c}\text { Stochastic mixed- } \\
\text { integer programming }\end{array}$ & & CPLEX \\
\hline $\begin{array}{l}\text { Atighehchian } \\
\text { et al. }\end{array}$ & 2019 & Sum of the expected ORs over and idle time costs & $\begin{array}{l}\text { Two-stage stochastic } \\
\text { programming }\end{array}$ & & L-shaped algorithm \\
\hline $\begin{array}{l}\text { Marchesi et } \\
\text { al. }\end{array}$ & 2020 & Minimize the total number of waiting patients & $\begin{array}{l}\text { Two-stage stochastic } \\
\text { programming }\end{array}$ & & SAA \\
\hline $\begin{array}{l}\text { Silva and De } \\
\text { souza }\end{array}$ & 2020 & Minimize total expected cost & $\begin{array}{l}\text { Stochastic dynamic } \\
\text { programming }\end{array}$ & & Dynamic programming \\
\hline Zhang et al. & 2020 & Minimize patient-related and hospital-related cost & $\begin{array}{c}\text { Stochastic } \\
\text { programming }\end{array}$ & & $\begin{array}{l}\text { Column-generation- } \\
\text { based heuristic }\end{array}$ \\
\hline Barrera et al. & 2020 & Minimize the cost of referrals to the private sector & $\begin{array}{l}\text { Stochastic dynamic } \\
\text { programming }\end{array}$ & & Heuristic algorithms \\
\hline $\begin{array}{l}\text { Khaniyev et } \\
\text { al. }\end{array}$ & 2020 & $\begin{array}{l}\text { Minimize the weighted sum of the room idle and } \\
\text { overtime, and expected patient waiting times }\end{array}$ & $\begin{array}{l}\text { Scenario-based } \\
\text { programming }\end{array}$ & & Heuristic algorithms \\
\hline $\begin{array}{l}\text { Present } \\
\text { research }\end{array}$ & 2021 & $\begin{array}{c}\text { Minimize the maximum completion time and the sum } \\
\text { of the earliness-tardiness time of the surgical } \\
\text { operations }\end{array}$ & $\begin{array}{l}\text { Robust optimization } \\
\text { approach }\end{array}$ & $\checkmark$ & $\begin{array}{l}\text { Multi-choice goal } \\
\text { programming (MCGP) } \\
\text { with utility function }\end{array}$ \\
\hline
\end{tabular}


Table 2

\begin{tabular}{|c|c|}
\hline Parameters & Values \\
\hline Number of ORs & 5,10 \\
\hline Number of beds in the recovery room & 5,10 \\
\hline Number of patients & $10,20,30$ \\
\hline Number of shared resources & $1,2,3$ \\
\hline
\end{tabular}


Table 3

\begin{tabular}{|c|c|c|c|c|c|c|c|c|c|c|c|c|c|c|}
\hline $\mathrm{TP}$ & NORs & NBRR & $\mathrm{NP}$ & NSR & {$\left[\Gamma_{1}, \Gamma_{2}\right]$} & $C_{\max }^{-}$ & $C_{\max }^{+}$ & $C_{\max }{ }^{\prime}$ & GAP & $E T^{-}$ & $E T^{+}$ & $E T^{\prime}$ & GAP & $\begin{array}{c}\text { Time } \\
\text { (second) }\end{array}$ \\
\hline \multirow{3}{*}{1} & \multirow{3}{*}{5} & \multirow{3}{*}{5} & \multirow{3}{*}{10} & \multirow{3}{*}{1} & $(0 \%, 0 \%)$ & 300 & 385 & 315 & $5.0 \%$ & 389 & 577 & 395 & $1.5 \%$ & 5.3 \\
\hline & & & & & $(50 \%, 50 \%)$ & 350 & 465 & 370 & $5.7 \%$ & 468.5 & 738 & 488.5 & $4.2 \%$ & 6.4 \\
\hline & & & & & $(100 \%, 100 \%)$ & 385 & 465 & 385 & $0.0 \%$ & 468.5 & 639.5 & 468.5 & $0.0 \%$ & 5.5 \\
\hline \multirow{3}{*}{2} & \multirow{3}{*}{5} & \multirow{3}{*}{5} & \multirow{3}{*}{10} & \multirow{3}{*}{2} & $(0 \%, 0 \%)$ & 205 & 255 & 255 & $24.3 \%$ & 317 & 375 & 375 & $18.2 \%$ & 5.1 \\
\hline & & & & & $(50 \%, 50 \%)$ & 245 & 360 & 360 & $46.9 \%$ & 378.5 & 399 & 399 & $5.4 \%$ & 9.2 \\
\hline & & & & & $(100 \%, 100 \%)$ & 245 & 370 & 370 & $51.0 \%$ & 378.5 & 429 & 429 & $13.3 \%$ & 5.7 \\
\hline \multirow{3}{*}{3} & \multirow{3}{*}{5} & \multirow{3}{*}{5} & \multirow{3}{*}{10} & \multirow{3}{*}{3} & $(0 \%, 0 \%)$ & 205 & 240 & 205 & $0.0 \%$ & 306.5 & 379 & 324 & $5.7 \%$ & 6.6 \\
\hline & & & & & $(50 \%, 50 \%)$ & 245 & 350 & 245 & $0.0 \%$ & 364.5 & 524.5 & 364 & $0.1 \%$ & 6.0 \\
\hline & & & & & $(100 \%, 100 \%)$ & 245 & 310 & 245 & $0.0 \%$ & 364.5 & 401 & 364.5 & $0.0 \%$ & 6.8 \\
\hline \multirow{3}{*}{4} & \multirow{3}{*}{5} & \multirow{3}{*}{5} & \multirow{3}{*}{20} & \multirow{3}{*}{1} & $(0 \%, 0 \%)$ & 680 & 715 & 690 & $1.4 \%$ & 2077 & 3421 & 2104 & $1.2 \%$ & 3000.0 \\
\hline & & & & & $(50 \%, 50 \%)$ & 795 & 925 & 800 & $0.6 \%$ & 2982.5 & 4111 & 2982.5 & $0.0 \%$ & 3001.0 \\
\hline & & & & & $(100 \%, 100 \%)$ & 815 & 840 & 815 & $0.0 \%$ & 2784.5 & 4236.5 & 2784.5 & $0.0 \%$ & 2240.0 \\
\hline \multirow{3}{*}{5} & \multirow{3}{*}{5} & & & & $(0 \%, 0 \%)$ & 590 & 620 & 590 & $0.0 \%$ & 1731.5 & 2885 & 1814.5 & $7.7 \%$ & 3000.0 \\
\hline & & 5 & 20 & 2 & $(50 \%, 50 \%)$ & 670 & 835 & 670 & $0.0 \%$ & 2356 & 3754.5 & 2356 & $0.0 \%$ & 1985.0 \\
\hline & & & & & $(100 \%, 100 \%)$ & 670 & 790 & 670 & $0.0 \%$ & 2044 & 3065 & 2188 & $7.0 \%$ & 3005.0 \\
\hline & & & & & $(0 \%, 0 \%)$ & 590 & 660 & 590 & $0.0 \%$ & 1693.5 & 2910 & 1758 & $3.8 \%$ & 2208.0 \\
\hline 6 & 5 & 5 & 20 & 3 & $(50 \%, 50 \%)$ & 670 & 700 & 670 & $0.0 \%$ & 2104.5 & 3223 & 2104.5 & $0.0 \%$ & 3000.0 \\
\hline & & & & & $(100 \%, 100 \%)$ & 670 & 745 & 670 & $0.0 \%$ & 2006.5 & 3666.5 & 2059 & $2.6 \%$ & 3001.0 \\
\hline & & & & & $(0 \%, 0 \%)$ & 895 & 10065 & 980 & $9.4 \%$ & 3996 & 6172.5 & 4836.5 & $21.0 \%$ & 3004.0 \\
\hline 7 & 5 & 5 & 30 & 1 & $(50 \%, 50 \%)$ & 1260 & 1375 & 1260 & $0.0 \%$ & 5920 & 9599 & 6441.5 & $8.8 \%$ & 3004.0 \\
\hline & & & & & $(100 \%, 100 \%)$ & 1110 & 1125 & 1110 & $0.0 \%$ & 7692 & 8304.5 & 7692 & $0.0 \%$ & 3005.0 \\
\hline & & & & & $(0 \%, 0 \%)$ & 825 & 10075 & 915 & $10.9 \%$ & 4002.5 & 5814.5 & 5343 & $33.4 \%$ & 3005.0 \\
\hline 8 & 5 & 5 & 30 & 2 & $(50 \%, 50 \%)$ & 980 & 1225 & 980 & $0.0 \%$ & 4741 & 7365.5 & 4741 & $0.0 \%$ & 3006.0 \\
\hline & & & & & $(100 \%, 100 \%)$ & 985 & 1260 & 985 & $0.0 \%$ & 5677.5 & 7209 & 5677.5 & $0.0 \%$ & 3007.0 \\
\hline & & & & & $(0 \%, 0 \%)$ & 825 & 10075 & 860 & $4.2 \%$ & 3523.5 & 5883 & 3664 & $3.9 \%$ & 3003.0 \\
\hline 9 & 5 & 5 & 30 & 3 & $(50 \%, 50 \%)$ & 950 & 1025 & 950 & $0.0 \%$ & 4464.5 & 6202.5 & 4690.5 & $5.0 \%$ & 3007.0 \\
\hline & & & & & $(100 \%, 100 \%)$ & 950 & 1115 & 950 & $0.0 \%$ & 4218 & 6365.5 & 5161 & $22.3 \%$ & 3004.0 \\
\hline & & & & & $(0 \%, 0 \%)$ & 300 & 325 & 305 & $1.6 \%$ & 389 & 633.5 & 428 & $10.0 \%$ & 13.6 \\
\hline 10 & 5 & 10 & 10 & 1 & $(50 \%, 50 \%)$ & 350 & 385 & 350 & $0.0 \%$ & 468.5 & 763.5 & 578 & $23.4 \%$ & 14.5 \\
\hline & & & & & $(100 \%, 100 \%)$ & 350 & 465 & 385 & $10.0 \%$ & 468.5 & 601.5 & 468.5 & $0.0 \%$ & 15.8 \\
\hline & & & & & $(0 \%, 0 \%)$ & 295 & 345 & 300 & $1.6 \%$ & 441.5 & 611 & 441.5 & $0.0 \%$ & 3.9 \\
\hline 11 & 5 & 10 & 10 & 2 & $(50 \%, 50 \%)$ & 340 & 380 & 340 & $0.0 \%$ & 557.5 & 795 & 559.5 & $0.3 \%$ & 12.8 \\
\hline & & & & & $(100 \%, 100 \%)$ & 340 & 430 & 340 & $0.0 \%$ & 557.5 & 683.5 & 559.5 & $0.3 \%$ & 11.0 \\
\hline & & & & & $(0 \%, 0 \%)$ & 295 & 345 & 295 & $0.0 \%$ & 437.5 & 520.5 & 439.5 & $0.4 \%$ & 4.1 \\
\hline 12 & 5 & 10 & 10 & 3 & $(50 \%, 50 \%)$ & 340 & 460 & 340 & $0.0 \%$ & 553.5 & 791 & 557.49 & $0.7 \%$ & 9.8 \\
\hline & & & & & $(100 \%, 100 \%)$ & 340 & 395 & 340 & $0.0 \%$ & 553.5 & 708.5 & 557.5 & $0.7 \%$ & 44.5 \\
\hline & & & & & $(0 \%, 0 \%)$ & 680 & 715 & 685 & $0.7 \%$ & 2140.5 & 2860 & 2763 & $29.0 \%$ & 3000.0 \\
\hline 13 & 5 & 10 & 20 & 1 & $(50 \%, 50 \%)$ & 800 & 955 & 800 & $0.0 \%$ & 3050.5 & 4529 & 3076 & $0.8 \%$ & 3000.1 \\
\hline & & & & & $(100 \%, 100 \%)$ & 790 & 965 & 795 & $0.6 \%$ & 2627 & 4064 & 2991 & $13.8 \%$ & 3002.1 \\
\hline
\end{tabular}




\begin{tabular}{|c|c|c|c|c|c|c|c|c|c|c|c|c|c|c|}
\hline \multirow{3}{*}{14} & \multirow{3}{*}{5} & \multirow{3}{*}{10} & \multirow{3}{*}{20} & \multirow{3}{*}{2} & $(0 \%, 0 \%)$ & 590 & 620 & 590 & $0.0 \%$ & 2014 & 2675 & 2014 & $0.0 \%$ & 2115.3 \\
\hline & & & & & $(50 \%, 50 \%)$ & 670 & 680 & 670 & $0.0 \%$ & 2124.5 & 2915 & 2124.5 & $0.0 \%$ & 2933.4 \\
\hline & & & & & $(100 \%, 100 \%)$ & 670 & 705 & 670 & $0.0 \%$ & 2076 & 3227 & 2152.5 & $3.6 \%$ & 3000.0 \\
\hline \multirow{3}{*}{15} & \multirow{3}{*}{5} & \multirow{3}{*}{10} & \multirow{3}{*}{20} & \multirow{3}{*}{3} & $(0 \%, 0 \%)$ & 745 & 770 & 745 & $0.0 \%$ & 2189 & 3703.5 & 2279 & $4.1 \%$ & 2077.5 \\
\hline & & & & & $(50 \%, 50 \%)$ & 840 & 935 & 840 & $0.0 \%$ & 2531.5 & 4296 & 2651.5 & $4.7 \%$ & 2831.3 \\
\hline & & & & & $(100 \%, 100 \%)$ & 840 & 860 & 840 & $0.0 \%$ & 2531.5 & 4208 & 2703 & $6.7 \%$ & 3000.0 \\
\hline \multirow{3}{*}{16} & \multirow{3}{*}{5} & \multirow{3}{*}{10} & \multirow{3}{*}{30} & \multirow{3}{*}{1} & $(0 \%, 0 \%)$ & 1095 & 68618.5 & 1360 & $24.0 \%$ & 3996 & 6621 & 6272 & $56.9 \%$ & 3007.1 \\
\hline & & & & & $(50 \%, 50 \%)$ & 1465 & 1695 & 1465 & $0.0 \%$ & 8523 & 9628.5 & 8523 & $0.0 \%$ & 2315.4 \\
\hline & & & & & $(100 \%, 100 \%)$ & 1375 & 1665 & 1375 & $0.0 \%$ & 8277 & 8504 & 8277 & $0.0 \%$ & 3004.1 \\
\hline \multirow{3}{*}{17} & \multirow{3}{*}{5} & \multirow{3}{*}{10} & \multirow{3}{*}{30} & \multirow{3}{*}{2} & $(0 \%, 0 \%)$ & 1010 & 60239.2 & 1260 & $24.7 \%$ & 5363 & 6498 & 6498 & $21.1 \%$ & 3005.0 \\
\hline & & & & & $(50 \%, 50 \%)$ & 1350 & 1400 & 1350 & $0.0 \%$ & 7829.5 & 9463 & 7829.5 & $0.0 \%$ & 2294.9 \\
\hline & & & & & $(100 \%, 100 \%)$ & 1150 & 2000 & 1150 & $0.0 \%$ & 6000 & 8742.5 & 6000 & $0.0 \%$ & 2505.7 \\
\hline & & & & & $(0 \%, 0 \%)$ & 1010 & 53832.5 & 1045 & $3.4 \%$ & 3979 & 7541.5 & 4145.5 & $4.1 \%$ & 3004.0 \\
\hline 18 & 5 & 10 & 30 & 3 & $(50 \%, 50 \%)$ & 1145 & 1405 & 1145 & $0.0 \%$ & 7430 & 8805 & 7430 & $0.0 \%$ & 2027.1 \\
\hline & & & & & $(100 \%, 100 \%)$ & 1135 & 1535 & 1140 & $0.4 \%$ & 7412 & 8265 & 7412 & $0.0 \%$ & 3006.1 \\
\hline & & & & & $(0 \%, 0 \%)$ & 390 & 395 & 390 & $0.0 \%$ & 483 & 779 & 494 & $2.2 \%$ & 7.3 \\
\hline 19 & 10 & 5 & 10 & 1 & $(50 \%, 50 \%)$ & 445 & 505 & 445 & $0.0 \%$ & 599 & 1053.5 & 642 & $7.1 \%$ & 15.3 \\
\hline & & & & & $(100 \%, 100 \%)$ & 445 & 500 & 445 & $0.0 \%$ & 599 & 982 & 642 & $7.1 \%$ & 12.2 \\
\hline & & & & & $(0 \%, 0 \%)$ & 305 & 385 & 305 & $0.0 \%$ & 359.5 & 460 & 359.5 & $0.0 \%$ & 3.4 \\
\hline 20 & 10 & 5 & 10 & 2 & $(50 \%, 50 \%)$ & 340 & 440 & 340 & $0.0 \%$ & 458.5 & 724.5 & 458.5 & $0.0 \%$ & 6.0 \\
\hline & & & & & $(100 \%, 100 \%)$ & 340 & 485 & 340 & $0.0 \%$ & 458.5 & 668.5 & 458.5 & $0.0 \%$ & 6.6 \\
\hline & & & & & $(0 \%, 0 \%)$ & 545 & 650 & 550 & $0.9 \%$ & 330 & 693 & 334 & $1.2 \%$ & 2.1 \\
\hline 21 & 10 & 5 & 10 & 3 & $(50 \%, 50 \%)$ & 575 & 580 & 575 & $0.0 \%$ & 428 & 1057 & 428 & $0.0 \%$ & 4.7 \\
\hline & & & & & $(100 \%, 100 \%)$ & 575 & 580 & 575 & $0.0 \%$ & 428 & 1162 & 428 & $0.0 \%$ & 3.3 \\
\hline & & & & & $(0 \%, 0 \%)$ & 670 & 795 & 685 & $2.2 \%$ & 2293 & 3408.5 & 2293 & $0.0 \%$ & 3000.4 \\
\hline 22 & 10 & 5 & 20 & 1 & $(50 \%, 50 \%)$ & 855 & 1060 & 855 & $0.0 \%$ & 2558 & 3798 & 2558 & $0.0 \%$ & 2365.1 \\
\hline & & & & & $(100 \%, 100 \%)$ & 865 & 910 & 865 & $0.0 \%$ & 2438.5 & 4254 & 2598 & $6.5 \%$ & 3001.2 \\
\hline & & & & & $(0 \%, 0 \%)$ & 440 & 480 & 445 & $1.1 \%$ & 1559.5 & 1924.5 & 1600.5 & $2.6 \%$ & 3002.4 \\
\hline 23 & 10 & 5 & 20 & 2 & $(50 \%, 50 \%)$ & 505 & 880 & 530 & $4.9 \%$ & 2059.5 & 2222.5 & 2059.5 & $0.0 \%$ & 2990.1 \\
\hline & & & & & $(100 \%, 100 \%)$ & 530 & 580 & 530 & $0.0 \%$ & 1807 & 2546 & 1871 & $3.4 \%$ & 3003.5 \\
\hline & & & & & $(0 \%, 0 \%)$ & 365 & 585 & 420 & $15.0 \%$ & 1199 & 1592.5 & 1202.5 & $0.2 \%$ & 3000.0 \\
\hline 24 & 10 & 5 & 20 & 3 & $(50 \%, 50 \%)$ & 435 & 620 & 485 & $11.4 \%$ & 1384 & 2067 & 1499.5 & $8.3 \%$ & 3000.1 \\
\hline & & & & & $(100 \%, 100 \%)$ & 430 & 650 & 435 & $1.1 \%$ & 1496.5 & 2167 & 1569 & $4.8 \%$ & 3000.7 \\
\hline & & & & & $(0 \%, 0 \%)$ & 1000 & 10065 & 1045 & $4.5 \%$ & 3152.5 & 6545 & 3728 & $18.2 \%$ & 3003.0 \\
\hline 25 & 10 & 5 & 30 & 1 & $(50 \%, 50 \%)$ & 1290 & 1615 & 1290 & $0.0 \%$ & 5328 & 7549.5 & 5328 & $0.0 \%$ & 3006.1 \\
\hline & & & & & $(100 \%, 100 \%)$ & 1190 & 2060 & 1190 & $0.0 \%$ & 5450.5 & 6545 & 5450.5 & $0.0 \%$ & 3007.9 \\
\hline & & & & & $(0 \%, 0 \%)$ & 740 & 10115 & 770 & $4.0 \%$ & 3099.5 & 5019 & 3505.5 & $0.0 \%$ & 3003.2 \\
\hline 26 & 10 & 5 & 30 & 2 & $(50 \%, 50 \%)$ & 1045 & 1440 & 1045 & $0.0 \%$ & 3829.5 & 5913 & 4068 & $6.2 \%$ & 3004.3 \\
\hline & & & & & $(100 \%, 100 \%)$ & 965 & 1355 & 965 & $0.0 \%$ & 4835 & 6342.5 & 4835 & $0.0 \%$ & 2235.7 \\
\hline & & & & & $(0 \%, 0 \%)$ & 650 & 10065 & 685 & $5.3 \%$ & 2190 & 3740 & 2672 & $22.0 \%$ & 3004.2 \\
\hline 27 & 10 & 5 & 30 & 3 & $(50 \%, 50 \%)$ & 725 & 850 & 750 & $3.4 \%$ & 2979 & 5223 & 3106 & $4.2 \%$ & 3006.0 \\
\hline & & & & & $(100 \%, 100 \%)$ & 725 & 845 & 725 & $0.0 \%$ & 2894.5 & 4447.5 & 2894.5 & $0.0 \%$ & 3007.5 \\
\hline 28 & 10 & 10 & 10 & 1 & $(0 \%, 0 \%)$ & 390 & 480 & 395 & $1.2 \%$ & 483 & 602.5 & 483 & $0.0 \%$ & 12.3 \\
\hline
\end{tabular}




\begin{tabular}{|c|c|c|c|c|c|c|c|c|c|c|c|c|c|c|}
\hline & & & & & $(50 \%, 50 \%)$ & 445 & 455 & 445 & $0.0 \%$ & 599 & 1145 & 642 & $7.1 \%$ & 20.3 \\
\hline & & & & & $(100 \%, 100 \%)$ & 445 & 475 & 445 & $0.0 \%$ & 599 & 1060 & 642 & $7.1 \%$ & 19.3 \\
\hline \multirow{3}{*}{29} & \multirow{3}{*}{10} & \multirow{3}{*}{10} & \multirow{3}{*}{10} & \multirow{3}{*}{2} & $(0 \%, 0 \%)$ & 350 & 485 & 365 & $4.2 \%$ & 456 & 622.5 & 456 & $0.0 \%$ & 11.7 \\
\hline & & & & & $(50 \%, 50 \%)$ & 405 & 460 & 410 & $1.2 \%$ & 577.5 & 1069.5 & 638 & $10.4 \%$ & 22.2 \\
\hline & & & & & $(100 \%, 100 \%)$ & 405 & 425 & 410 & $1.2 \%$ & 577.5 & 990.5 & 638.5 & $10.5 \%$ & 17.8 \\
\hline \multirow{3}{*}{30} & \multirow{3}{*}{10} & \multirow{3}{*}{10} & \multirow{3}{*}{10} & \multirow{3}{*}{3} & $(0 \%, 0 \%)$ & 300 & 415 & 310 & $3.3 \%$ & 377 & 513 & 426.5 & $13.1 \%$ & 10.8 \\
\hline & & & & & $(50 \%, 50 \%)$ & 335 & 550 & 365 & $8.9 \%$ & 490.5 & 737 & 516.5 & $5.3 \%$ & 16.1 \\
\hline & & & & & $(100 \%, 100 \%)$ & 335 & 585 & 365 & $8.9 \%$ & 490.5 & 740.5 & 516.5 & $5.3 \%$ & 15.6 \\
\hline \multirow{3}{*}{31} & \multirow{3}{*}{10} & \multirow{3}{*}{10} & \multirow{3}{*}{20} & \multirow{3}{*}{1} & $(0 \%, 0 \%)$ & 670 & 720 & 685 & $2.2 \%$ & 2067 & 3494 & 2487 & $20.3 \%$ & 3003.1 \\
\hline & & & & & $(50 \%, 50 \%)$ & 910 & 1000 & 910 & $0.0 \%$ & 2838.5 & 5112.5 & 2838.5 & $0.0 \%$ & 2104.4 \\
\hline & & & & & $(100 \%, 100 \%)$ & 860 & 955 & 860 & $0.0 \%$ & 2761 & 4555.5 & 2761 & $0.0 \%$ & 2152.1 \\
\hline \multirow{3}{*}{32} & \multirow{3}{*}{10} & \multirow{3}{*}{10} & \multirow{3}{*}{20} & \multirow{3}{*}{2} & $(0 \%, 0 \%)$ & 435 & 510 & 445 & $2.2 \%$ & 1527.5 & 2022 & 1621 & $6.1 \%$ & 3003.2 \\
\hline & & & & & $(50 \%, 50 \%)$ & 545 & 655 & 545 & $0.0 \%$ & 1876.9 & 2433.5 & 2024 & $7.8 \%$ & 3003.1 \\
\hline & & & & & $(100 \%, 100 \%)$ & 525 & 1035 & 525 & $0.0 \%$ & 2025.5 & 2618 & 2025.5 & $0.0 \%$ & 2562.0 \\
\hline \multirow{3}{*}{33} & \multirow{3}{*}{10} & \multirow{3}{*}{10} & \multirow{3}{*}{20} & \multirow{3}{*}{3} & $(0 \%, 0 \%)$ & 365 & 455 & 395 & $8.2 \%$ & 1166 & 1695 & 1313.5 & $13.6 \%$ & 3003.3 \\
\hline & & & & & $(50 \%, 50 \%)$ & 430 & 495 & 430 & $0.0 \%$ & 1413 & 2135.5 & 1602 & $13.3 \%$ & 3007.1 \\
\hline & & & & & $(100 \%, 100 \%)$ & 429.9 & 545 & 465 & $8.1 \%$ & 1405.5 & 2000.9 & 1616 & $14.9 \%$ & 3003.2 \\
\hline \multirow{3}{*}{34} & \multirow{3}{*}{10} & \multirow{3}{*}{10} & \multirow{3}{*}{30} & & $(0 \%, 0 \%)$ & 805 & 60013.5 & 855 & $6.2 \%$ & 3233 & 4878.5 & 3386 & $4.7 \%$ & 3008.4 \\
\hline & & & & 1 & $(50 \%, 50 \%)$ & 1010 & 1375 & 1010 & $0.0 \%$ & 4786 & 4878.5 & 4786 & $0.0 \%$ & 3008.2 \\
\hline & & & & & $(100 \%, 100 \%)$ & 985 & 1135 & 985 & $0.0 \%$ & 3884.5 & 4878.5 & 4523.5 & $16.4 \%$ & 3007.6 \\
\hline & & & & & $(0 \%, 0 \%)$ & 535 & 83550.6 & 760 & $42.0 \%$ & 2633 & 3565.5 & 3409.5 & $29.4 \%$ & 3006.1 \\
\hline 35 & 10 & 10 & 30 & 2 & $(50 \%, 50 \%)$ & 735 & 1265 & 735 & $0.0 \%$ & 3375.5 & 5820.5 & 3375.5 & $0.0 \%$ & 2387.4 \\
\hline & & & & & $(100 \%, 100 \%)$ & 1070 & 83550.6 & 1070 & $0.0 \%$ & 3940 & 5000 & 4929 & $25.1 \%$ & 3006.1 \\
\hline & & & & & $(0 \%, 0 \%)$ & 490 & 73969.8 & 490 & $0.0 \%$ & 2061 & 3245.5 & 2154.5 & $4.5 \%$ & 3000.2 \\
\hline 36 & 10 & 10 & 30 & 3 & $(50 \%, 50 \%)$ & 540 & 995 & 540 & $0.0 \%$ & 2988 & 3837.5 & 2988 & $0.0 \%$ & 2054.3 \\
\hline & & & & & $(100 \%, 100 \%)$ & 540 & 935 & 540 & $0.0 \%$ & 3571 & 4075.5 & 3571 & $0.0 \%$ & 2395.4 \\
\hline
\end{tabular}

TP: Test problem, NORs: Number of ORs, NBRR: Number of beds in the recovery room, NP: Number of patients, NSR: Number of shared resources, $\left[\Gamma_{1}, \Gamma_{2}\right]$ : Uncertainty levels, $C_{\max }^{-}$: The ideal negative value of the first objective function, $C_{\max }^{+}$: The ideal positive value of the first objective function, $C_{\max }{ }^{\prime}$ : The obtained value of the first objective function, $E T^{-}$: The ideal negative value of the second objective function, $E T^{+}$: The ideal positive value of the second objective function, $E T^{\prime}$ : The obtained value of the second objective function, GAP: The gap between the objective function and the ideal negative value. 


\section{Table 4}

\begin{tabular}{|c|c|c|}
\hline Floor & Types of surgeries & Number of ORs \\
\hline \multirow{3}{*}{ First Floor } & Orthopedics & 3 \\
\cline { 2 - 3 } & General surgery & 2 \\
\cline { 2 - 3 } & Urology & 1 \\
\cline { 2 - 3 } & Neurosurgery & 1 \\
\hline \multirow{2}{*}{ Second floor } & General surgery & 1 \\
\cline { 2 - 3 } & Kidney transplant & 1 \\
\hline
\end{tabular}


Table 5

\begin{tabular}{|c|c|}
\hline Patient status & Weight \\
\hline Patients with unstable condition & 1 \\
\hline Elderly patients and pediatric patients & {$[0.5,1]$} \\
\hline Patients with stable condition & Less than 0.5 \\
\hline
\end{tabular}


Table 6

\begin{tabular}{|c|c|c|c|}
\hline \multirow{5}{*}{ Surgery times in ORs } & Type of surgery & Minimum surgery time & Minimum surgery time \\
\cline { 2 - 4 } & Orthopedics & 30 & 240 \\
\cline { 2 - 3 } & Urology & 15 & 270 \\
\cline { 2 - 3 } & Neurosurgery & 30 & 360 \\
\cline { 2 - 3 } & General surgery & 30 & 300 \\
\cline { 2 - 3 } & Kidney transplant & 180 & 300 \\
\hline \multirow{2}{*}{ Hospitalization time in the recovery room } & Type of surgery & Minimum time & Maximum time \\
\cline { 2 - 4 } & All surgeries & 10 & 120 \\
\hline
\end{tabular}


Table 7

\begin{tabular}{|c|c|c|c|c|c|c|c|c|}
\hline \multirow{2}{*}{ Day } & \multirow{2}{*}{$\begin{array}{l}\text { Number } \\
\text { of } \\
\text { patients }\end{array}$} & \multirow{2}{*}{$\begin{array}{l}\text { Number of } \\
\text { patients that } \\
\text { need shared } \\
\text { resource }\end{array}$} & \multicolumn{3}{|c|}{$C_{\max }{ }^{\prime}$} & \multicolumn{3}{|c|}{$E T^{\prime}$} \\
\hline & & & $\begin{array}{l}\text { Proposed } \\
\text { approach }\end{array}$ & $\begin{array}{c}\text { Current } \\
\text { approach }\end{array}$ & Improvement & $\begin{array}{l}\text { Proposed } \\
\text { approach }\end{array}$ & $\begin{array}{c}\text { Current } \\
\text { approach }\end{array}$ & Improvement \\
\hline 1 & 30 & 4 & 765 & 820 & $7.8 \%$ & 3308 & 3774 & $12.33 \%$ \\
\hline 2 & 20 & 3 & 665 & 780 & $14.74 \%$ & 1699 & 1990 & $14.62 \%$ \\
\hline 3 & 17 & 3 & 630 & 700 & $10 \%$ & 1184 & 1250 & $5.28 \%$ \\
\hline 4 & 12 & 3 & 615 & 675 & $7.4 \%$ & 890 & 950 & $6.31 \%$ \\
\hline 5 & 10 & 2 & 540 & 610 & $11.47 \%$ & 477 & 540 & $11.66 \%$ \\
\hline
\end{tabular}


Table 8

\begin{tabular}{|c|c|c|c|c|c|}
\hline Case & Description & $\mathrm{NP}$ & NBRR & NSR & NORs \\
\hline 1 & Base case & 30 & 7 & 1 & 9 \\
\hline 2 & \multirow{2}{*}{ Sensitivity analysis on the number of shared resources } & 30 & 7 & 2 & 9 \\
\hline 3 & & 30 & 7 & 3 & 9 \\
\hline 4 & \multirow{2}{*}{ Sensitivity analysis on the ORs (use lower-load OR to help other ORs) } & 30 & 7 & 1 & 9 \\
\hline 5 & & 30 & 7 & 1 & 9 \\
\hline
\end{tabular}


Table 9

\begin{tabular}{|c|c|c|c|c|c|c|c|c|c|}
\hline Case & NOR & NBRR & NP & NSR & {$\left[\Gamma_{1}, \Gamma_{2}\right]$} & $C_{\max }{ }^{\prime}$ & Percentage of change & $E T^{\prime}$ & Percentage of change \\
\hline 1 & 9 & 7 & 30 & 1 & $(50 \%, 50 \%)$ & 1030 & - & 4664.5 & - \\
\hline 2 & 9 & 7 & 30 & 2 & $(50 \%, 50 \%)$ & 695 & $-32.5 \%$ & 3636 & $-22 \%$ \\
\hline 3 & 9 & 7 & 30 & 3 & $(50 \%, 50 \%)$ & 590 & $-42.7 \%$ & 3359.5 & $-27.9 \%$ \\
\hline
\end{tabular}


Table 10

\begin{tabular}{|c|c|c|c|c|c|c|c|c|c|}
\hline Case & NOR & NBRR & NP & NSR & {$\left[\Gamma_{1}, \Gamma_{2}\right]$} & $C_{\max }{ }^{\prime}$ & Percentage of change & $E T^{\prime}$ & Percentage of change \\
\hline 1 & 9 & 7 & 30 & 1 & $(50 \%, 50 \%)$ & 1030 & - & 4664.5 & - \\
\hline 4 & 9 & 7 & 30 & 1 & $(50 \%, 50 \%)$ & 1025 & $-0.4 \%$ & 4478 & $-3.9 \%$ \\
\hline 5 & 9 & 7 & 30 & 1 & $(50 \%, 50 \%)$ & 985 & $-4.3 \%$ & 4508 & $-3.3 \%$ \\
\hline
\end{tabular}

